\title{
Synthesis and antibacterial activity screening of quaternary ammonium derivatives of triazolyl pyranochromenones
}

\author{
PREETI YADAV ${ }^{\mathrm{a}}$, BIPUL KUMAR ${ }^{\mathrm{b}}$, HEMANT K GAUTAM ${ }^{\mathrm{b}}$ and SUNIL K SHARMA ${ }^{\mathrm{a}, *}$ \\ ${ }^{a}$ Department of Chemistry, University of Delhi, Delhi 110 007, India \\ ${ }^{\mathrm{b}}$ CSIR-Institute of Genomics and Integrative Biology, Sukhdev Vihar, Mathura Road, Delhi 110 025, India \\ Email: sksharma@chemistry.du.ac.in
}

MS received 14 May 2016; revised 24 September 2016; accepted 23 November 2016

\begin{abstract}
A series of quaternary ammonium derivatives of triazolyl pyranochromen-2-ones have been synthesized and characterized; their antibacterial potential were investigated against two gram negative (Pseudomonas aeruginosa and Escherichia coli) and two gram positive bacterial strains (Bacillus cereus and Staphylococcus aureus). In order to develop structure-activity relationship (SAR), the effect of varying the substituent (R) at the $\mathrm{C}-10$ position of pyranochromen-2-one as well as the length of the spacer (n) between the triazolyl pyranochromen-2-ones and quaternary ammonium group, on the antibacterial activity of compounds has been evaluated. Some of the screened compounds exhibited antibacterial potential against the studied strains in the microgram range.
\end{abstract}

Keywords. Quaternary ammonium derivatives; triazolyl pyranochromen-2-ones; antibacterial activity; structure-activity relationship (SAR).

\section{Introduction}

Over the years, the development of newer antimicrobial agents has drawn interest from the researchers in both academia and industry, due to the increasing bacterial resistance to antibiotics. Quaternary ammonium compounds (QACs) are known for their antimicrobial activity and widely used as disinfectants to control microbial growth. ${ }^{1,2}$ QACs possess a broad spectrum antimicrobial activity against a variety of gram-positive and gram-negative bacteria, as well as some pathogenic species of fungi and protozoa. ${ }^{3,4}$ Both ionic and hydrophobic interactions between the QACs and microbial walls or cytoplasmic membranes lead to cell death or malfunctions in cellular processes. ${ }^{5}$

Chromenone derivatives, structurally similar to clinical anti-infective quinolone drugs, as a new type of antibiotics have received specific interest along with the dramatically rising prevalence of multi-drug resistant microbial infections. ${ }^{6}$ In nature, many important antibiotics containing the chromenone skeleton are present, such as novobiocin (1), chlorobiocin (2) and coumermycin A1 (3) (Figure 1), but they are not used in clinic owing to their relatively weak activity towards gram-negative bacteria, poor water solubility and side effects. ${ }^{7}$ Thus, attempts are being made by

\footnotetext{
*For correspondence
}

researchers working in the relevant field to develop newer chromenone derivatives that possess more effective antibiotic potential.

Our group has earlier reported the synthesis of a series of novel ammonium derivatives of chromen-2ones, quinolin-2-ones and chromen-4-ones and studied their activity against a series of bacterial and fungal pathogens. ${ }^{8-11}$ Amongst all screened compounds, four compounds viz., 4, 5, 6, and 7 (Figure 2) were found to be most promising, however compounds $\mathbf{5}, \mathbf{6}$, and 7 were found to be toxic. Although the potency of the compound $\mathbf{4}$ is less than that of the commercial drugs amphotericin B and kanamycin, it was found to have a broader range of activity than these drugs among the fungal and bacterial strains tested. Also the cytotoxicity studies revealed that the compound $\mathbf{4}$ is safer than the standard antifungal drug amphotericin B. ${ }^{8}$

In order to get the insight of mechanism of action of these derivatives, we studied the effect of the most potent compound 4 [ $N, N, N$-triethyl-11-(4-methyl-2oxo-2 $H$-chromen-7-yloxy)-11-oxoundecan-1-aminium bromide] (SCD-1) on the proteome of pathogen Aspergillus fumigatus. ${ }^{9,10}$ On treatment with A. fumigatus, 4 completely inhibited the expression of four proteins of crucial metabolic processes i.e., Cdc48, UlaA, V-ATPase and Ugp1, and decreased the abundance of two proteins belonging to the pathogen specific riboflavin synthesis pathway. Thus, these proteins could 


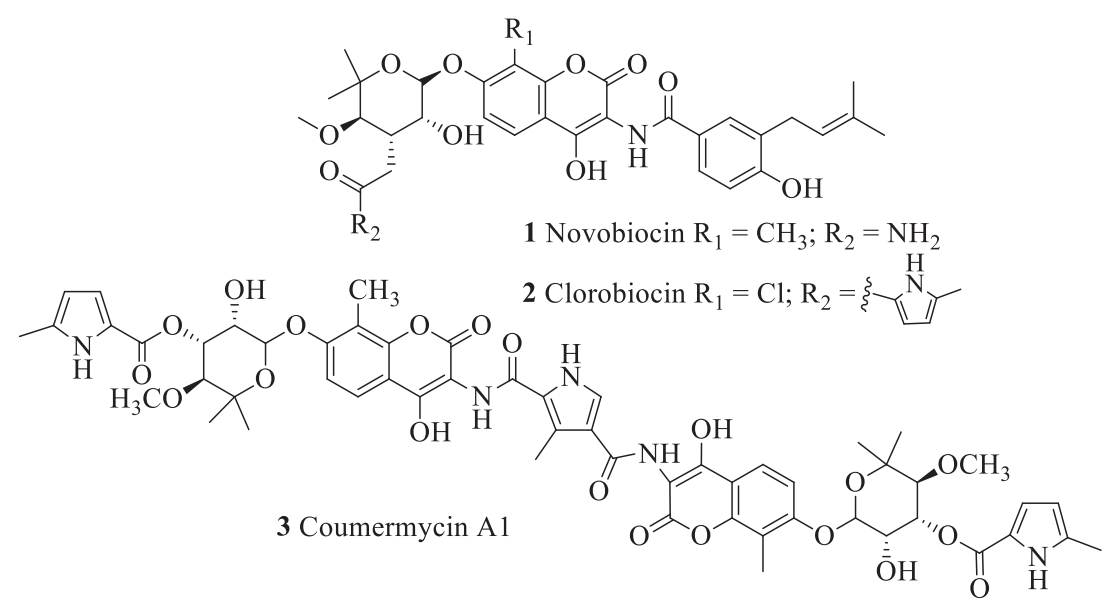

Figure 1. Structure of naturally occurring antibiotics containing the chromenone skeleton.

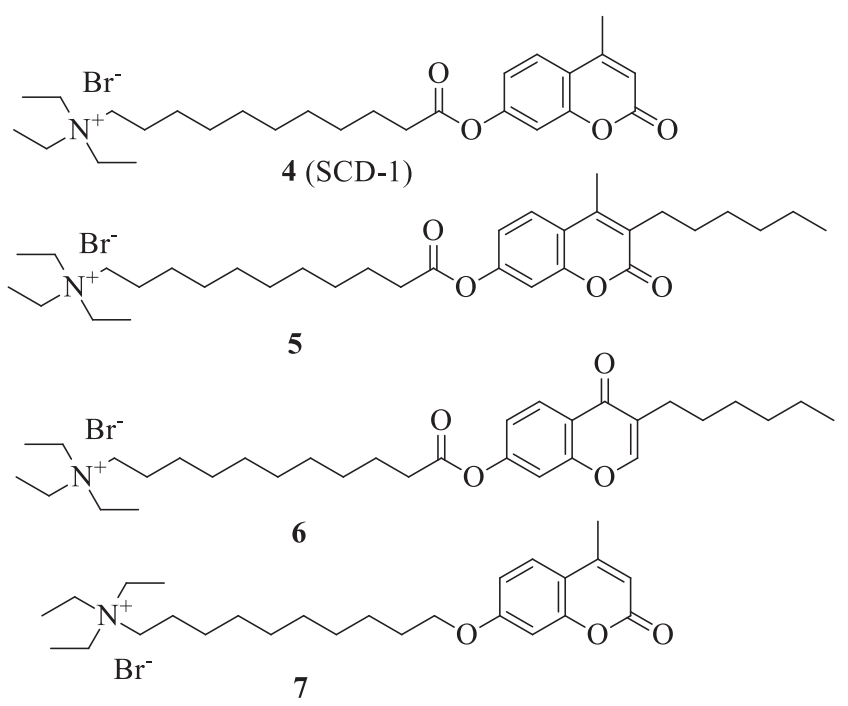

Figure 2. Structure of most promising antimicrobial compounds synthesized by our group. ${ }^{8}$

be considered as important molecular targets of $\mathbf{4}$ in $A$. fumigatus. Furthermore, the in vivo safety and antifungal efficacy of $\mathbf{4}$ has also been evaluated, and the results suggested that it is quite safe antifungal compound. ${ }^{10}$ This study further warrants the validation of different target molecules that are the analogues of 4 . Furthermore, the combination of chromen-2-one backbone with nitrogen containing heterocyclic compounds such as triazoles, azetidine, thiazolidine, thiazole, etc. has also been explored to improve the antimicrobial efficiency of resulting combinations of chromophores. ${ }^{12-15}$ A number of drugs such as fluconazole, voriconazole and itraconazole having triazole ring have been prevalently used in the anti-infective therapy. ${ }^{16}$

The above observations and our interest in the development of antimicrobial agents prompted us to design and synthesize a series of newer quaternary ammonium derivatives of pyranochromen-2-one by following the Click chemistry approach that involve coupling of 4-azido methyl pyranochromen-2-ones with bromoacetylenes. The resulting bromo triazolyl pranochromenone derivatives were then converted to quaternary ammonium ions. The synthesized quaternary ammonium compounds and their corresponding bromo-precursors were evaluated for antibacterial activity against four human pathogenic bacterial strains.

\section{Experimental}

\subsection{Materials}

All of the chemicals and reagents were procured from Spectrochem Pvt. Ltd. and Sigma-Aldrich. The organic solvents were dried and distilled prior to their use. Reactions were monitored by precoated TLC plates (Merck silica gel $\left.60 \mathrm{~F}_{254}\right)$; the spots were visualized by UV light. Silica gel (100-200 mesh) was used for column chromatography.

\subsection{Instruments}

Melting points were measured on a Buchi M-560 instrument and are uncorrected. Infrared spectra were recorded on a Perkin-Elmer FT-IR Model 9 spectrometer. The ${ }^{1} \mathrm{H}$ NMR and ${ }^{13} \mathrm{C}$ NMR spectra were recorded on a Jeol-400 (400 $\mathrm{MHz}, 100.5 \mathrm{MHz}$ ) using tetramethylsilane as the internal standard. The chemical shift values are on a $\delta$ scale and the coupling constant values $(J)$ are in hertz. The HRMS data were recorded on Agilent-6530, Q-TOF LCMS. UV-Visible absorption spectra were recorded using a Cary 300 UV-Vis spectrophotometer from Agilent Technologies.

\subsection{Synthetic procedures}

\subsubsection{Synthesis of compounds $\mathbf{1 0}$ and $\mathbf{1 1}$}

To the stirred solution of resorcinol $(\mathbf{8})(2 \mathrm{~g}, 18.16 \mathrm{mmol}) /$ pyrogallol (9) $(2 \mathrm{~g}, 15.86 \mathrm{mmol})$ in xylene $(15 \mathrm{~mL}), \mathrm{H}_{3} \mathrm{PO}_{4}$ (3.5 equivalent) was added. The resulting reaction mixture was stirred for $20 \mathrm{~min}$ at $25^{\circ} \mathrm{C}$, followed by the addition of 
a solution of 2-methyl-1,3-butadiene (isoprene) (1.2 equivalent) dissolved in xylene $(10 \mathrm{~mL})$. After complete addition of isoprene, the reaction mixture was allowed to stir for another $12 \mathrm{~h}$ at $25^{\circ} \mathrm{C}$. The progress of the reaction was monitored by TLC $\left(\mathrm{MeOH}: \mathrm{CHCl}_{3}, 1: 49\right)$. On completion of the reaction, the reaction mixture was neutralized by using $5 \% \mathrm{NaHCO}_{3}$ in water. The resulting reaction mixture was extracted with ethyl acetate $(3 \times 100 \mathrm{~mL})$. The organic layer was combined and dried over anhydrous $\mathrm{Na}_{2} \mathrm{SO}_{4}$ and the solvent was removed under reduced pressure to get the crude product, which was purified by column chromatography. The desired product 10/11 was obtained as an off-white solid in 94/92\% isolated yield. ${ }^{17}$

2.3.1a 2,2-Dimethylchroman-7-ol (10): $\quad$ M.p.: $66-67^{\circ} \mathrm{C}$ (literature M.p.:- $\left.67-68^{\circ} \mathrm{C}\right)^{17}$; UV $(\mathrm{MeOH}) \lambda_{\max }: 207,283$ $\mathrm{nm}$; IR (KBr) $v_{\max }: 3379.56,2975.55,2929.81,1622.33$, $1594.96,1506.82,1454.84,1302.67,1230.82,1148.87$, 1114.24, 991.38, $843.81 \mathrm{~cm}^{-1} ;{ }^{1} \mathrm{H} \mathrm{NMR}\left(\mathrm{CDCl}_{3}, 400 \mathrm{MHz}\right)$ : $\delta 1.32\left(\mathrm{~s}, 6 \mathrm{H}, 2 \times \mathrm{CH}_{3}\right), 1.76(\mathrm{t}, 2 \mathrm{H}, J=6.8 \mathrm{~Hz}, \mathrm{H}-3), 2.68$ (t, 2H, $J=6.8 \mathrm{~Hz}, \mathrm{H}-4), 6.26$ (d, 1H, $J=2.2 \mathrm{~Hz}, \mathrm{H}-8), 6.33$ $(\mathrm{dd}, 1 \mathrm{H}, J=2.2 \& 8.4 \mathrm{~Hz}, \mathrm{H}-6), 6.89$ (d, $1 \mathrm{H}, J=8.4 \mathrm{~Hz}$, $\mathrm{H}-5) ;{ }^{13} \mathrm{C} \mathrm{NMR}\left(\mathrm{CDCl}_{3}, 100.5 \mathrm{MHz}\right): \delta 21.68(\mathrm{C}-4), 26.77$ $\left(2 \times \mathrm{CH}_{3}\right), 32.86(\mathrm{C}-3), 74.41(\mathrm{C}-2), 103.70(\mathrm{C}-8), 107.32$ (C-6), 113.26 (C-10), 130.08 (C-5), 154.64, 154.76 (C-7, C-9); HRMS: Calculated for $\mathrm{C}_{11} \mathrm{H}_{14} \mathrm{O}_{2}[\mathrm{M}+\mathrm{H}]^{+}$179.1072, found 179.1073 .

2.3.1b 2,2-Dimethylchroman-7,8-diol (11): M.p.: 102$104^{\circ} \mathrm{C}$ (literature M.p. $\left.106-108^{\circ} \mathrm{C}\right)^{17}$; UV (MeOH) $\lambda_{\max }$ : 214, $271 \mathrm{~nm}$; IR (KBr) $v_{\max }: 3427.75,2974.28$, 2925.41, $1626.57,1510.59$, 1465.61, 1345.04, 1272.25, 1239.26, $1190.47,1151.37,1118.61,1056.00,1017.39$, 984.02, $792.41 \mathrm{~cm}^{-1} ;{ }^{1} \mathrm{H} \mathrm{NMR}\left(\mathrm{CDCl}_{3}, 400 \mathrm{MHz}\right): \delta 1.34(\mathrm{~s}, 6 \mathrm{H}$, $\left.2 \times \mathrm{CH}_{3}\right), 1.79(\mathrm{t}, 2 \mathrm{H}, J=6.8 \mathrm{~Hz}, \mathrm{H}-3), 2.70(\mathrm{t}, 2 \mathrm{H}, J$ $=6.8 \mathrm{~Hz}, \mathrm{H}-4), 6.45(\mathrm{~d}, 1 \mathrm{H}, J=8.4 \mathrm{~Hz}, \mathrm{H}-6), 6.51(\mathrm{~d}$, $1 \mathrm{H}, J=8.4 \mathrm{~Hz}, \mathrm{H}-5) ;{ }^{13} \mathrm{C} \mathrm{NMR}\left(\mathrm{CDCl}_{3}, 100.5 \mathrm{MHz}\right): \delta$ 21.50 (C-4), $26.83\left(2 \times \mathrm{CH}_{3}\right), 32.96(\mathrm{C}-3), 75.46(\mathrm{C}-2)$, 107.04 (C-6), 113.05 (C-10), 119.52 (C-5), 131.69 (C-8), 141.18, 141.88 (C-7, C-9); HRMS: Calculated for $\mathrm{C}_{11} \mathrm{H}_{14} \mathrm{O}_{3}$ $[\mathrm{M}+\mathrm{H}]^{+}$195.1021, found 195.1046.

\subsubsection{Synthesis of compounds $\mathbf{1 2}$ and $\mathbf{1 3}$}

The compound $\mathbf{1 0}$ (2 g, $11.22 \mathrm{mmol}) / \mathbf{1 1}$ (2 g, $10.30 \mathrm{mmol})$ and 4-chloroethyl acetoacetate (1.1 equivalent) were taken in a round bottom flask and the mixture was cooled to $0^{\circ} \mathrm{C}$. Conc. $\mathrm{H}_{2} \mathrm{SO}_{4}(8 \mathrm{~mL})$ was then added dropwise with the temperature of reaction mixture maintained at $0^{\circ} \mathrm{C}$. On completion of the addition, the mixture was stirred at room temperature $\left(25-30^{\circ} \mathrm{C}\right)$ for $8 \mathrm{~h}$. The reaction was monitored on TLC $\left(\mathrm{MeOH}: \mathrm{CHCl}_{3}, 1: 49\right)$, on completion of the reaction, the contents of the flask were poured over crushed ice. The solid so obtained $(\mathbf{1 2 / 1 3})$ was filtered, washed with water, dried under vacuum and purified by column chromatography. The desired product $\mathbf{1 2 / 1 3}$ was obtained as an off white solid in $95 / 94 \%$ isolated yield. ${ }^{18}$ 2.3.2a 4-(Chloromethyl)-8,8-dimethyl-7,8-dihydropyrano [3,2-g]chromen-2(6H)-one (12): M.p.: $178-180^{\circ} \mathrm{C}$ (literature M.p.: $\left.183-184^{\circ} \mathrm{C}\right)^{19}$; UV (MeOH) $\lambda_{\max }: 205,336$ $\mathrm{nm}$; IR (KBr) $v_{\max }: 2974.72,2940.92,1709.41,1622.90$, 1566.33, 1374.98, 1288.77, 1154.34, 1116.79, 924.44, 839.30, $757.59 \mathrm{~cm}^{-1} ;{ }^{1} \mathrm{H} \mathrm{NMR}\left(\mathrm{CDCl}_{3}, 400 \mathrm{MHz}\right): \delta 1.35$ $\left(\mathrm{s}, 6 \mathrm{H}, 2 \times \mathrm{CH}_{3}\right), 1.83(\mathrm{t}, 2 \mathrm{H}, J=6.8 \mathrm{~Hz}, \mathrm{H}-7), 2.83(\mathrm{t}, 2 \mathrm{H}, J$ $=6.8 \mathrm{~Hz}, \mathrm{H}-6), 4.57\left(\mathrm{~s}, 2 \mathrm{H}, \mathrm{CH}_{2} \mathrm{Cl}\right), 6.32(\mathrm{~s}, 1 \mathrm{H}, \mathrm{H}-3), 6.73$ (s, 1H, H-10), 7.31 (s, 1H, H-5); ${ }^{13} \mathrm{C} \mathrm{NMR}\left(\mathrm{CDCl}_{3}, 100.5\right.$ $\mathrm{MHz}): \delta 22.11(\mathrm{C}-6), 26.86\left(2 \times \mathrm{CH}_{3}\right), 32.34(\mathrm{C}-7), 41.39$ $\left(\mathrm{CH}_{2} \mathrm{Cl}\right), 75.93$ (C-8), 105.00 (C-10), 110.27 (C-12), 112.38 (C-3), 118.51 (C-14), 124.63 (C-5), 149.43 (C-11), 153.82 (C-13), 157.96 (C-4), 161.12 (C-2); HRMS: Calculated for $\mathrm{C}_{15} \mathrm{H}_{15} \mathrm{ClO}_{3}[\mathrm{M}+\mathrm{H}]^{+}$279.0788, found 279.1599.

2.3.2b 4-(Chloromethyl)-10-hydroxy-8,8-dimethyl-7,8dihydropyrano[3,2-g]chromen-2(6H)-one (13): M.p.: 243-244 ${ }^{\circ} \mathrm{C}$; UV (MeOH) $\lambda_{\max }: 211,265,335 \mathrm{~nm}$; IR (KBr) $\nu_{\max }: 3527.40,2977.38,1719.91,1635.67,1589.40,1464.09$, $1351.13,1272.30,1185.57,1157.95,1118.38,1098.13$, 1036.92, 922.71, 884.12, 847.92 $\mathrm{cm}^{-1} ;{ }^{1} \mathrm{H} \mathrm{NMR}\left(\mathrm{CDCl}_{3}\right.$, $400 \mathrm{MHz}): \delta 1.40\left(\mathrm{~s}, 6 \mathrm{H}, 2 \times \mathrm{CH}_{3}\right), 1.87(\mathrm{t}, 2 \mathrm{H}, J=6.8 \mathrm{~Hz}$, $\mathrm{H}-7), 2.84$ (t, 2H, $J=6.8 \mathrm{~Hz}, \mathrm{H}-6), 4.58\left(\mathrm{~s}, 2 \mathrm{H}, \mathrm{CH}_{2} \mathrm{Cl}\right)$, 6.36 (s, 1H, H-3), 6.91 (s, 1H, H-5); ${ }^{13} \mathrm{C} \mathrm{NMR}\left(\mathrm{CDCl}_{3}, 100.5\right.$ $\mathrm{MHz}): \delta 22.01$ (C-6), $26.85\left(2 \times \mathrm{CH}_{3}\right), 32.46(\mathrm{C}-7), 41.39$ $\left(\mathrm{CH}_{2} \mathrm{Cl}\right), 76.81(\mathrm{C}-8), 110.41(\mathrm{C}-12), 112.61(\mathrm{C}-3), 114.48$ (C-5), 118.13 (C-14), 132.47 (C-10), 140.33 (C-11), 144.67 (C-13), 149.89 (C-4), 160.17 (C-2); HRMS: Calculated for $\mathrm{C}_{15} \mathrm{H}_{15} \mathrm{ClO}_{4}[\mathrm{M}+\mathrm{H}]^{+}$295.0737, found 295.0737.

\subsubsection{Synthesis of compound 14}

To the solution of compound $\mathbf{1 3}(1 \mathrm{~g}, 3.40 \mathrm{mmol})$ in anhydrous acetone $(30 \mathrm{~mL})$ at room temperature, anhydrous potassium carbonate (1.5 equivalent) was added. After stirring the reaction mixture for $10 \mathrm{~min}$, methyl iodide (1.2 equivalent) was added dropwise. The reaction mixture was stirred for $18 \mathrm{~h}$ at room temperature $\left(25-30^{\circ} \mathrm{C}\right)$. The progress of the reaction was monitored on TLC $\left(\mathrm{MeOH}: \mathrm{CHCl}_{3}, 1\right.$ : 49). On completion of the reaction, the reaction mixture was poured on ice cold water and the precipitated product was filtered. The obtained crude product was washed with water $(2 \times 20 \mathrm{~mL})$ followed by hexane $(2 \times 20 \mathrm{~mL})$ and the pure compound was collected as a light yellow solid in $94 \%$ isolated yield.

2.3.3a 4-(Chloromethyl)-10-methoxy-8,8-dimethyl-7,8dihydropyrano[3,2-g]chromen-2(6H)-one (14): M.p.: $181-182^{\circ} \mathrm{C}$; IR $(\mathrm{KBr}) v_{\max }: 2927.42,2855.95,1724.76$, $1611.78,1569.27,1453.03,1392.08,1156.58,1113.83$, 1050.78, $755.43 \mathrm{~cm}^{-1} ;{ }^{1} \mathrm{H}$ NMR $\left(\mathrm{CDCl}_{3}, 400 \mathrm{MHz}\right): \delta 1.40$ $\left(\mathrm{s}, 6 \mathrm{H}, 2 \times \mathrm{CH}_{3}\right), 1.85(\mathrm{t}, 2 \mathrm{H}, J=6.8 \mathrm{~Hz}, \mathrm{H}-7), 2.84(\mathrm{t}$, $2 \mathrm{H}, J=6.8 \mathrm{~Hz}, \mathrm{H}-6), 3.90\left(\mathrm{~s}, 3 \mathrm{H}, \mathrm{OCH}_{3}\right), 4.57(\mathrm{~s}, 2 \mathrm{H}$, $\mathrm{CH}_{2} \mathrm{Cl}$ ), 6.34 (s, $\left.1 \mathrm{H}, \mathrm{H}-3\right), 7.08$ (s, $\left.1 \mathrm{H}, \mathrm{H}-5\right) ;{ }^{13} \mathrm{C}$ NMR $\left(\mathrm{CDCl}_{3}, 100.5 \mathrm{MHz}\right): \delta 22.31(\mathrm{C}-6), 26.85\left(2 \times \mathrm{CH}_{3}\right), 32.24$ $(\mathrm{C}-7), 41.39\left(\mathrm{CH}_{2} \mathrm{Cl}\right), 61.17\left(\mathrm{OCH}_{3}\right), 76.10(\mathrm{C}-8), 110.36$ 
(C-12), 112.56 (C-3), 118.57 (C-5), 118.97 (C-14), 135.72 (C-10), 146.32, 149.58 (C-11, C-13), 151.04 (C-4), 160.52 (C-2); HRMS: Calculated for $\mathrm{C}_{16} \mathrm{H}_{17} \mathrm{ClO}_{4}[\mathrm{M}+\mathrm{H}]^{+}$ 309.0894, found 309.0905.

\subsubsection{Synthesis of compounds 15-17}

The compound $\mathbf{1 2}$ (1g, $3.60 \mathrm{mmol}) / \mathbf{1 3}(1 \mathrm{~g}, 3.40 \mathrm{mmol}) / \mathbf{1 4}$ $(1 \mathrm{~g}, 3.25 \mathrm{mmol})$ was dissolved in anhydrous acetone, to this sodium azide ( 1.5 equivalent) was added. The resulting reaction mixture was stirred for $12-18 \mathrm{~h}$ at $40^{\circ} \mathrm{C}$. On completion of the reaction, the reaction mixture was poured on ice cold water and the desired product was filtered, washed with water $(2 \times 20 \mathrm{~mL})$, followed by hexane $(2 \times 20 \mathrm{~mL})$. The desired product (15-17) was obtained in 85-90\% isolated yield.

2.3.4a 4-(Azidomethyl)-8,8-dimethyl-7,8-dihydropyrano [3,2-g]chromen-2(6H)-one (15): M.p.: 157-158 ${ }^{\circ}$; UV $(\mathrm{MeOH}) \lambda_{\max }: 206,333 \mathrm{~nm}$; IR (KBr) $v_{\max }: 2976.47$, 2939.32, 2108.56, 1700.25, 1618.26, 1557.84, 1391.59, 1319.35, 1151.05, 1115.29, 1044.17, 927.21, 887.19, 842.77, $753.70 \mathrm{~cm}^{-1} ;{ }^{1} \mathrm{H} \mathrm{NMR}\left(\mathrm{CDCl}_{3}, 400 \mathrm{MHz}\right): \delta 1.34(\mathrm{~s}$, $\left.6 \mathrm{H}, 2 \times \mathrm{CH}_{3}\right), 1.83(\mathrm{t}, 2 \mathrm{H}, J=6.8 \mathrm{~Hz}, \mathrm{H}-7), 2.82$ $(\mathrm{t}, 2 \mathrm{H}, J=6.8 \mathrm{~Hz}, \mathrm{H}-6), 4.45\left(\mathrm{~s}, 2 \mathrm{H}, \mathrm{CH}_{2} \mathrm{~N}_{3}\right), 6.28$ (s, 1H, H-3), 6.73 (s, 1H, H-10), 7.19 (s, 1H, H-5); ${ }^{13} \mathrm{C} \mathrm{NMR}\left(\mathrm{CDCl}_{3}, 100.5 \mathrm{MHz}\right): \delta 22.09$ (C-6), 26.85 $\left(2 \times \mathrm{CH}_{3}\right), 32.34(\mathrm{C}-7), 50.89\left(\mathrm{CH}_{2} \mathrm{~N}_{3}\right), 75.92(\mathrm{C}-8), 105.00$ (C-10), 110.34 (C-12), 111.37 (C-3), 118.63 (C-14), 124.32 (C-5), 148.31 (C-11), 153.76 (C-13), 157.98 (C-4), 160.99 (C-2); HRMS: Calculated for $\mathrm{C}_{15} \mathrm{H}_{15} \mathrm{~N}_{3} \mathrm{O}_{3}[\mathrm{M}+\mathrm{H}]^{+}$ 286.1192, found 286.1180.

2.3.4b 4-(Azidomethyl)-10-hydroxy-8,8-dimethyl-7,8dihydropyrano[3,2-g]chromen-2(6H)-one (16): M.p.: 194-195 ${ }^{\circ} \mathrm{C}$; UV (MeOH) $\lambda_{\max }: 210,264,332 \mathrm{~nm}$; IR $(\mathrm{KBr}) \nu_{\max }: 3528.03,2975.25,2106.84,1712.25,1625.59$, $1581.25,1457.77,1406.32,1351.59,1267.14,1157.21$, 1113.27, 1034.39, 927.40, 882.83, $754.00 \mathrm{~cm}^{-1} ;{ }^{1} \mathrm{H}$ NMR $\left(\mathrm{CDCl}_{3}, 400 \mathrm{MHz}\right): \delta 1.39\left(\mathrm{~s}, 6 \mathrm{H}, 2 \times \mathrm{CH}_{3}\right), 1.86(\mathrm{t}, 2 \mathrm{H}$, $J=6.8 \mathrm{~Hz}, \mathrm{H}-7), 2.82(\mathrm{t}, 2 \mathrm{H}, J=6.8 \mathrm{~Hz}, \mathrm{H}-6), 4.46(\mathrm{~s}$, $2 \mathrm{H}, \mathrm{CH}_{2} \mathrm{~N}_{3}$ ), 6.30 (s, 1H, H-3), 6.79 (s, 1H, H-5); ${ }^{13} \mathrm{C} \mathrm{NMR}$ $\left(\mathrm{CDCl}_{3}, 100.5 \mathrm{MHz}\right): \delta 21.98(\mathrm{C}-6), 26.85\left(2 \times \mathrm{CH}_{3}\right)$, 32.45 (C-7), $50.84\left(\mathrm{CH}_{2} \mathrm{~N}_{3}\right), 76.81$ (C-8), 110.47 (C-12), 111.55 (C-3), 114.15 (C-5), 118.13 (C-14), 132.45 (C-10), 140.29 (C-11), 144.74 (C-13), 148.77 (C-4), 159.98 (C-2); HRMS: Calculated for $\mathrm{C}_{15} \mathrm{H}_{15} \mathrm{~N}_{3} \mathrm{O}_{4}[\mathrm{M}+\mathrm{H}]^{+} 302.1141$, found 302.1147 .

2.3.4c 4-(Azidomethyl)-10-methoxy-8,8-dimethyl-7,8dihydropyrano[3,2-g]chromen-2(6H)-one (17): M.p.: $187-188^{\circ} \mathrm{C}$; UV (MeOH) $\lambda_{\max }: 209,331 \mathrm{~nm}$; IR (KBr) $v_{\max }$ : 2973.06, 2935.31, 2110.05, 1713.79, 1613.36, 1570.93, $1452.78,1396.04,1344.63,1224.89,1188.44,1156.93$, 938.17, 849.09, $756.38 \mathrm{~cm}^{-1} ;{ }^{1} \mathrm{H} \mathrm{NMR}\left(\mathrm{CDCl}_{3}, 400 \mathrm{MHz}\right)$ : $\delta 1.39\left(\mathrm{~s}, 6 \mathrm{H}, 2 \times \mathrm{CH}_{3}\right), 1.84(\mathrm{t}, 2 \mathrm{H}, J=7.2 \mathrm{~Hz}, \mathrm{H}-7), 2.82$ $(\mathrm{t}, 2 \mathrm{H}, J=7.2 \mathrm{~Hz}, \mathrm{H}-6), 3.91\left(\mathrm{~s}, 3 \mathrm{H}, \mathrm{OCH}_{3}\right), 4.44(\mathrm{~s}, 2 \mathrm{H}$, $\left.\mathrm{CH}_{2} \mathrm{~N}_{3}\right), 6.29$ (s, 1H, H-3), 6.96 (s, 1H, H-5); ${ }^{13} \mathrm{C} \mathrm{NMR}$ $\left(\mathrm{CDCl}_{3}, 100.5 \mathrm{MHz}\right): \delta 22.31(\mathrm{C}-6), 26.87\left(2 \times \mathrm{CH}_{3}\right)$,
32.27 (C-7), $50.91\left(\mathrm{CH}_{2} \mathrm{~N}_{3}\right), 61.19\left(\mathrm{OCH}_{3}\right), 76.11(\mathrm{C}-8)$, 110.48 (C-12), 111.55 (C-3), 118.23 (C-5), 119.00 (C-14), 135.96 (C-10), 146.44, 148.49 (C-11, C-13), 151.10 (C-4), 160.39 (C-2); HRMS: Calculated for $\mathrm{C}_{16} \mathrm{H}_{17} \mathrm{~N}_{3} \mathrm{O}_{4}[\mathrm{M}+\mathrm{H}]^{+}$ 316.1297 , found 316.1219 .

\subsubsection{Synthesis of compounds 18 and 19}

To a stirred mixture of dibromoalkane (2.5 equivalent) (1,6-dibromohexane or 1,10-dibromodecane), 50\% aqueous $\mathrm{NaOH}\left(2.5 \mathrm{~g}\right.$ in $5 \mathrm{~mL}$ water) and TBAI $(50 \mathrm{mg})$ at $50^{\circ} \mathrm{C}$, propargyl alcohol (1 g, $17.8 \mathrm{mmol})$ was added dropwise. The resulting reaction mixture was stirred at $50^{\circ} \mathrm{C}$ for overnight. The reaction was monitored on TLC (EtOAc : Petroleum ether; 1:9). On completion of the reaction, the reaction mixture was allowed to cool to attain room temperature. The contents were transferred to separating funnel and to it diethyl ether $(200 \mathrm{~mL})$ and brine solution $(100 \mathrm{~mL})$ were added and the layers were allowed to separate. The resulting organic layer was washed with water $(2 \times 100 \mathrm{~mL})$ and dried over anhydrous $\mathrm{Na}_{2} \mathrm{SO}_{4}$. The solvent was removed under reduced pressure to get the crude product, which was purified by column chromatography. The desired product 18/19 was obtained as a colorless liquid in 60/64 \% isolated yield.

2.3.5a 1-Bromo-6-(prop-2-yn-1-yloxy)hexane (18): IR (KBr) $v_{\max }: 3296.18,2925.21,2860.40,1460.92,1234.10$, $1088.82 \mathrm{~cm}^{-1} ;{ }^{1} \mathrm{H}$ NMR $\left(\mathrm{CDCl}_{3}, 400 \mathrm{MHz}\right): \delta 1.36-1.45(\mathrm{~m}$, $4 \mathrm{H}, \mathrm{H}-3$ \& H-4), 1.56-1.61 (m, 2H, H-5), 1.79-1.87 (m, 2H, $\mathrm{H}-2), 2.39$ (t, 1H, $\left.J=2.5 \mathrm{~Hz}, \mathrm{H}-3^{\prime}\right), 3.37$ (t, $2 \mathrm{H}, J=6.6 \mathrm{~Hz}$, $\mathrm{H}-6), 3.48$ (t, 2H, $J=6.6 \mathrm{~Hz}, \mathrm{H}-1), 4.09$ (d, 2H, $J=2.2 \mathrm{~Hz}$, $\left.\mathrm{H}-1^{\prime}\right) ;{ }^{13} \mathrm{C} \mathrm{NMR}\left(\mathrm{CDCl}_{3}, 100.5 \mathrm{MHz}\right): \delta 25.44(\mathrm{C}-3), 28.06$ (C-4), 29.45 (C-5), 32.83 (C-2), 34.04 (C-1), 58.18 (C-1'), 70.10 (C-6), 74.30 (C-3'), 80.08 (C-2'); HRMS: Calculated for $\mathrm{C}_{9} \mathrm{H}_{15} \mathrm{BrO}[\mathrm{M}+\mathrm{H}]^{+}$219.0385, found 219.0370.

\subsection{5b 1-Bromo-10-(prop-2-yn-1-yloxy)decane (19):} IR (KBr) $v_{\max }$ : 3297.08, 2926.21, 2854.40, 1458.92, 1240.10, $1097.71 \mathrm{~cm}^{-1}$; ${ }^{1} \mathrm{H}$ NMR $\left(\mathrm{CDCl}_{3}, 400 \mathrm{MHz}\right): \delta$ 1.26-1.40 (m, 12H, H-3-H-8), 1.52-1.57 (m, 2H, H-9), 1.78-1.85 (m, 2H, H-2), 2.39 (t, 1H, $\left.J=2.2 \mathrm{~Hz}, \mathrm{H}-3^{\prime}\right), 3.37$ (t, 2H, $J=6.8 \mathrm{~Hz}, \mathrm{H}-10), 3.47$ (t, 2H, $J=6.8 \mathrm{~Hz}, \mathrm{H}-1), 4.10$ $\left(\mathrm{d}, 2 \mathrm{H}, J=1.5 \mathrm{~Hz}, \mathrm{H}-1^{\prime}\right) ;{ }^{13} \mathrm{C} \mathrm{NMR}\left(\mathrm{CDCl}_{3}, 100.5 \mathrm{MHz}\right)$ : $\delta$ 26.03, 28.13, 28.71, 29.34, 29.41, 29.47 (C-3, C-4, C-5, C-6, C-7, C-8, C-9), 32.79 (C-2), 34.09 (C-1), 57.99 (C-1'), 70.26 (C-10), 74.04 (C-3'), 80.01 (C-2'); HRMS: Calculated for $\mathrm{C}_{13} \mathrm{H}_{23} \mathrm{BrO}\left[\mathrm{M}+\mathrm{NH}_{4}\right]^{+}$292.1276, found 292.1263.

\subsubsection{Synthesis of compounds 20-25}

To the solution of bromo alkyne 18/19 (1 equivalent) in THF : $\mathrm{H}_{2} \mathrm{O}(3: 1)$, the respective azide derivative (15-17) (1 equivalent) was added, followed by the addition of sodium ascorbate ( 0.4 equivalent) and $\mathrm{CuSO}_{4} .5 \mathrm{H}_{2} \mathrm{O}(0.2$ equivalent $)$ with constant stirring at $50^{\circ} \mathrm{C}$ for $18-24 \mathrm{~h}$. On completion of the reaction, observed through $\mathrm{TLC}$, the solvent was removed under reduced pressure. The residue so obtained was washed 
with saturated solution of EDTA and extracted with ethyl acetate $(3 \times 100 \mathrm{~mL})$. The organic layers were combined and dried over anhydrous sodium sulphate, and the solvent removed under reduced pressure to get the desired product as a crude solid. The crude product was purified by column chromatography by using a mixture of methanol and chloroform to get the desired compound in $80-85 \%$ isolated yield.

2.3.6a 4-((4-((6-Bromohexyloxy)methyl)-1H-1,2,3-triazol1-yl)methyl)-8,8-dimethyl-7,8-dihydropyrano[3,2-g] chromen-2(6H)-one (20): Yield = 83\%; M.p.: 174$175^{\circ} \mathrm{C}$; UV (MeOH) $\lambda_{\max }$ : 206, $335 \mathrm{~nm}$; IR (KBr) $v_{\max }$ : 2924.59, 2854.90, 1720.10, 1620.34, 1564.34, 1498.72, 1395.18, 1287.98, 1148.24, 1113.78, 929.19, 883.27, 817.45, $745.99 \mathrm{~cm}^{-1} ;{ }^{1} \mathrm{H} \mathrm{NMR}\left(\mathrm{CDCl}_{3}, 400 \mathrm{MHz}\right): \delta 1.32-$ $1.40\left(\mathrm{~m}, 10 \mathrm{H}, 2 \times \mathrm{CH}_{3}, \mathrm{H}-3^{\prime \prime}, \mathrm{H}-4^{\prime \prime}\right), 1.53-1.61(\mathrm{~m}, 2 \mathrm{H}$, H-2"), 1.77-1.84 (m, 4H, H-5", H-7), 2.77 (t, 2H, $J=6.4$ $\mathrm{Hz}, \mathrm{H}-6), 3.36$ (t, 2H, $\left.J=6.4 \mathrm{~Hz}, \mathrm{H}-1^{\prime \prime}\right), 3.49$ (t, $2 \mathrm{H}, J=6.8$ $\left.\mathrm{Hz}, \mathrm{H}-6^{\prime \prime}\right), 4.59$ (s, 2H, 4'a-CH $), 5.61$ (s, 2H, 4a- $\mathrm{CH}_{2}$ ), 5.83 (s, 1H, H-3), 6.71 (s, 1H, H-10), 7.29 (s, 1H, H-5), 7.58 $\left(\mathrm{s}, 1 \mathrm{H}, \mathrm{H}-5^{\prime}\right) ;{ }^{13} \mathrm{C} \mathrm{NMR}\left(\mathrm{CDCl}_{3}, 100.5 \mathrm{MHz}\right): \delta 22.02(\mathrm{C}-6)$, $25.25\left(\mathrm{C}-4^{\prime \prime}\right), 26.83\left(2 \times \mathrm{CH}_{3}\right), 27.85\left(\mathrm{C}-3^{\prime \prime}\right), 29.34\left(\mathrm{C}-2^{\prime \prime}\right)$, 32.21 (C-7), $32.57\left(\mathrm{C}-5^{\prime \prime}\right), 33.94\left(\mathrm{C}-6^{\prime \prime}\right), 50.34\left(4 \mathrm{a}-\mathrm{CH}_{2}\right)$, $64.16\left(4^{\prime} \mathrm{a}-\mathrm{CH}_{2}\right), 70.83\left(\mathrm{C}-1^{\prime \prime}\right), 76.11$ (C-8), 105.06 (C-10), 109.93 (C-12), 111.81 (C-3), 118.92 (C-14), 122.82 $\left(\mathrm{C}-5^{\prime}\right), 124.16$ (C-5), 146.41 (C-4'), 147.59 (C-11), 153.74, 158.37 (C-4, C-13), 160.56 (C-2); HRMS: Calculated for $\mathrm{C}_{24} \mathrm{H}_{30} \mathrm{BrN}_{3} \mathrm{O}_{4}[\mathrm{M}+\mathrm{H}+2]^{+}$506.1498, found 506.1481.

2.3.6b 4-((4-((10-Bromodecyloxy)methyl)-1H-1,2,3triazol-1-yl)methyl)-8,8-dimethyl-7,8-dihydropyrano [3,2-g]chromen-2(6H)-one (21): Yield = 85\%; M.p.: $166-167^{\circ} \mathrm{C}$; UV (MeOH) $\lambda_{\max }: 205,335 \mathrm{~nm}$; IR (KBr) $v_{\max }$ : 2927.44, 2856.09, 1726.53, 1624.66, 1567.44, 1441.75, $1329.14,1152.76,1119.75,931.97,886.09 \mathrm{~cm}^{-1} ;{ }^{1} \mathrm{H}$ NMR $\left(\mathrm{CDCl}_{3}, 400 \mathrm{MHz}\right): \delta 1.24-1.38\left(\mathrm{~m}, 18 \mathrm{H}, 2 \times \mathrm{CH}_{3}, \mathrm{H}-3^{\prime \prime}-\right.$ H-8 ${ }^{\prime \prime}$ ), 1.52-1.56 (m, 2H, H-2" ), 1.79-1.82 (m, 4H, H-9", H-7), 2.78 (t, 2H, $J=6.8 \mathrm{~Hz}, \mathrm{H}-6), 3.37$ (t, 2H, $J=6.8$ $\left.\mathrm{Hz}, \mathrm{H}-10^{\prime \prime}\right), 3.49$ (t, 2H, J = 6.8 Hz, H-1"), 4.60 (s, 2H, $\left.4^{\prime} \mathrm{a}-\mathrm{CH}_{2}\right), 5.60\left(\mathrm{~s}, 2 \mathrm{H}, 4 \mathrm{a}-\mathrm{CH}_{2}\right), 5.86(\mathrm{~s}, 1 \mathrm{H}, \mathrm{H}-3), 6.72$ (s, 1H, H-10), 7.29 (s, 1H, H-5), 7.56 (s, 1H, H-5'); ${ }^{13} \mathrm{C}$ $\mathrm{NMR}\left(\mathrm{CDCl}_{3}, 100.5 \mathrm{MHz}\right): \delta 22.00(\mathrm{C}-6), 25.99\left(\mathrm{C}-8^{\prime \prime}\right)$, $26.81\left(2 \times \mathrm{CH}_{3}\right), 28.06,28.65,29.28,29.31\left(\mathrm{C}-3^{\prime \prime}, \mathrm{C}-4^{\prime \prime}\right.$, C-5", C-6", C-7"), 29.52 (C-2"), 32.20 (C-7), 32.73 (C-9"), $34.09\left(\mathrm{C}-10^{\prime \prime}\right), 50.29\left(4 \mathrm{a}-\mathrm{CH}_{2}\right), 64.17\left(4^{\prime} \mathrm{a}-\mathrm{CH}_{2}\right), 71.11$ $\left(\mathrm{C}-1^{\prime \prime}\right), 76.08$ (C-8), 105.03 (C-10), 109.94 (C-12), 111.75 (C-3), 118.89 (C-14), 122.78 (C-5'), 124.17 (C-5), 146.42 (C-4'), 147.66 (C-11), 153.71, 158.33 (C-4, C-13), 160.55 (C-2); HRMS: Calculated for $\mathrm{C}_{28} \mathrm{H}_{38} \mathrm{BrN}_{3} \mathrm{O}_{4}[\mathrm{M}+\mathrm{H}+2]^{+}$ 562.2124 , found 562.2099 .

2.3.6c 4-((4-((6-Bromohexyloxy)methyl)-1H-1,2,3triazol-1-yl)methyl)-10-hydroxy-8,8-dimethyl-7,8-dihydropyrano[3,2-g]chromen-2(6H)-one (22): Yield $=80 \%$; M.p.: $183-184^{\circ} \mathrm{C}$; UV (MeOH) $\lambda_{\max }$ : $209,265,333 \mathrm{~nm}$; IR $(\mathrm{KBr}) \nu_{\max }: 1706.29,1623.86,1581.15,1459.49,1401.40$,
$1354.14,1275.05,1189.89,1097.14,1039.06,884.05$, 801.19, $753.43 \mathrm{~cm}^{-1} ;{ }^{1} \mathrm{H}$ NMR (DMSO- $\left.d_{6}, 400 \mathrm{MHz}\right): \delta$ 1.27-1.36 (m, 10H, $\left.2 \times \mathrm{CH}_{3}, \mathrm{H}-3^{\prime \prime}, \mathrm{H}-4^{\prime \prime}\right), 1.46-1.50(\mathrm{~m}$, 2H, H-2") $1.74-1.82$ (m, 4H, H-5", H-7), 2.77 (t, 2H, $J=$ $6.8 \mathrm{~Hz}, \mathrm{H}-6), 3.41$ (t, 2H, $\left.J=6.8 \mathrm{~Hz}, \mathrm{H}-1^{\prime \prime}\right), 3.48(\mathrm{t}, 2 \mathrm{H}$, $\left.J=6.8 \mathrm{~Hz}, \mathrm{H}-6^{\prime \prime}\right), 4.50\left(\mathrm{~s}, 2 \mathrm{H}, 4^{\prime} \mathrm{a}-\mathrm{CH}_{2}\right), 5.49(\mathrm{~s}, 1 \mathrm{H}$, $\mathrm{H}-3), 5.85$ (s, 2H, 4a-CH $), 7.11$ (s, 1H, H-5), 8.22 (s, 1H, $\left.\mathrm{H}-5^{\prime}\right) ;{ }^{13} \mathrm{C}$ NMR (DMSO- $\left.d_{6}, 100.5 \mathrm{MHz}\right): \delta 21.66$ (C-6), $24.78\left(\mathrm{C}-4^{\prime \prime}\right), 26.54\left(2 \times \mathrm{CH}_{3}\right), 27.33\left(\mathrm{C}-3^{\prime \prime}\right), 28.92\left(\mathrm{C}-2^{\prime \prime}\right)$, 31.78 (C-7), $32.16\left(\mathrm{C}-5^{\prime \prime}\right), 35.10\left(\mathrm{C}-6^{\prime \prime}\right), 49.13\left(4 \mathrm{a}-\mathrm{CH}_{2}\right)$, $63.18\left(4^{\prime} \mathrm{a}-\mathrm{CH}_{2}\right), \quad 69.40 \quad\left(\mathrm{C}-1^{\prime \prime}\right), \quad 75.72(\mathrm{C}-8), \quad 109.74$ (C-12), 109.93 (C-3), 114.26 (C-5), 118.11 (C-14), 124.98 (C-5'), 132.92 (C-10), 140.95 (C-4'), 144.71 (C-11), 146.04 (C-13), 150.73 (C-4), 159.70 (C-2); HRMS: Calculated for $\mathrm{C}_{24} \mathrm{H}_{30} \mathrm{BrN}_{3} \mathrm{O}_{5}[\mathrm{M}+\mathrm{H}]^{+}$520.1447, found 520.1448, $[\mathrm{M}+\mathrm{H}+2]^{+}$522.1447, found 522.1433.

2.3.6d 4-((4-((10-Bromodecyloxy)methyl)-1H-1,2,3triazol-1-yl)methyl)-10-hydroxy-8,8-dimethyl-7,8-dihydropyrano[3,2-g]chromen-2(6H)-one (23): Yield $=82 \%$; M.p.: $193-194^{\circ} \mathrm{C}$; UV (MeOH) $\lambda_{\max }$ : $210,261,333 \mathrm{~nm}$; IR (KBr) $v_{\max }: 3144.40,1709.40,1626.15,1583.03,1461.41$, 1358.50, 1282.29, 1190.88, 1098.47, 998.99, 881.77, 758.24 $\mathrm{cm}^{-1} ;{ }^{1} \mathrm{H}$ NMR (DMSO- $\left.d_{6}, 400 \mathrm{MHz}\right): \delta 1.21-1.32(\mathrm{~m}$, $\left.18 \mathrm{H}, 2 \times \mathrm{CH}_{3}, \mathrm{H}-3^{\prime \prime}-\mathrm{H}-8^{\prime \prime}\right), 1.43-1.46$ (m, 2H, H-2" $), 1.73-$ 1.82 (m, 4H, H-9", H-7), 2.77 (t, 2H, J=6.8 Hz, H-6), 3.39 $\left(\mathrm{t}, 2 \mathrm{H}, J=6.8 \mathrm{~Hz}, \mathrm{H}-10^{\prime \prime}\right), 3.49$ (t, $\left.2 \mathrm{H}, J=6.8 \mathrm{~Hz}, \mathrm{H}-1^{\prime \prime}\right)$, $4.50\left(\mathrm{~s}, 2 \mathrm{H}, 4^{\prime} \mathrm{a}-\mathrm{CH}_{2}\right), 5.48\left(\mathrm{~s}, 2 \mathrm{H}, 4 \mathrm{a}-\mathrm{CH}_{2}\right), 5.85(\mathrm{~s}, 1 \mathrm{H}$, H-3), 7.11 (s, 1H, H-5), 8.22 (s, 1H, H-5'), 9.19 (s, 1H, OH); ${ }^{13} \mathrm{C}$ NMR (DMSO- $d_{6}, 100.5 \mathrm{MHz}$ ): $\delta 21.70$ (C-6), 25.66 $\left(\mathrm{C}-8^{\prime \prime}\right), 26.58\left(2 \times \mathrm{CH}_{3}\right), 27.54,28.12,28.82,28.86,28.92$ (C-3", C-4", C-5", C-6", C-7"), 29.12 (C-2"), 31.83 (C-7), $32.27\left(\mathrm{C}-9^{\prime \prime}\right), 35.25\left(\mathrm{C}-10^{\prime \prime}\right), 49.19\left(4 \mathrm{a}-\mathrm{CH}_{2}\right), 63.20\left(4^{\prime} \mathrm{a}\right.$ $\left.-\mathrm{CH}_{2}\right), 69.56\left(\mathrm{C}-1^{\prime \prime}\right), 75.76(\mathrm{C}-8), 109.76(\mathrm{C}-12), 110.03$

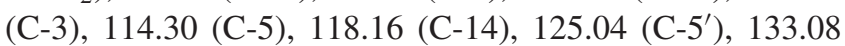
(C-10), 140.98 (C-4'), 144.77 (C-11), 146.08 (C-13), 150.79 (C-4), 159.84 (C-2); HRMS: Calculated for $\mathrm{C}_{28} \mathrm{H}_{38} \mathrm{BrN}_{3} \mathrm{O}_{5}$ $[\mathrm{M}+\mathrm{H}+2]^{+}$578.2073, found 578.2062.

2.3.6e 4-((4-((6-Bromohexyloxy)methyl)-1H-1,2,3triazol-1-yl)methyl)-10-methoxy-8,8-dimethyl-7,8-dihydropyrano[3,2-g]chromen-2(6H)-one (24): Yield = 82\%; M.p.: $168-169^{\circ} \mathrm{C}$; UV (MeOH) $\lambda_{\max }: 209,266,333$ $\mathrm{nm}$; IR $(\mathrm{KBr}) v_{\max }: 2929.98,2857.84,1721.28,1614.17$, $1571.42,1455.34,1403.81,1353.29,1220.13,1112.04$, 1047.97, 758.05 $\mathrm{cm}^{-1} ;{ }^{1} \mathrm{H} \mathrm{NMR}\left(\mathrm{CDCl}_{3}, 400 \mathrm{MHz}\right): \delta 1.34-$ $1.41\left(\mathrm{~m}, 10 \mathrm{H}, 2 \times \mathrm{CH}_{3}, \mathrm{H}-3^{\prime \prime}, \mathrm{H}-4^{\prime \prime}\right), 1.56-1.60(\mathrm{~m}, 2 \mathrm{H}$, $\mathrm{H}-2^{\prime \prime}$ ), 1.80-1.84 (m, 4H, H-5", H-7), 2.79 (t, 2H, $J=6.8$ $\mathrm{Hz}, \mathrm{H}-6), 3.37$ (t, 2H, $\left.J=6.8 \mathrm{~Hz}, \mathrm{H}-1^{\prime \prime}\right), 3.50$ (t, 2H, $J=6.8$ $\left.\mathrm{Hz}, \mathrm{H}-6^{\prime \prime}\right), 3.89$ (s, 3H, $\left.\mathrm{OCH}_{3}\right), 4.60$ (s, 2H, 4'a- $\left.\mathrm{CH}_{2}\right), 5.60$ (s, 2H, 4a- $\mathrm{CH}_{2}$ ), 5.84 (s, 1H, H-3), 7.06 (s, 1H, H-5), 7.57 (s, $\left.1 \mathrm{H}, \mathrm{H}-5^{\prime}\right) ;{ }^{13} \mathrm{C} \mathrm{NMR}\left(\mathrm{CDCl}_{3}, 100.5 \mathrm{MHz}\right): \delta 22.26$ (C-6), $25.27\left(\mathrm{C}-4^{\prime \prime}\right), 26.86\left(2 \times \mathrm{CH}_{3}\right), 27.87\left(\mathrm{C}-3^{\prime \prime}\right), 29.36\left(\mathrm{C}-2^{\prime \prime}\right)$, 32.14 (C-7), $32.59\left(\mathrm{C}-5^{\prime \prime}\right), 33.95\left(\mathrm{C}-6^{\prime \prime}\right), 50.26\left(4 \mathrm{a}-\mathrm{CH}_{2}\right)$, $61.20\left(\mathrm{OCH}_{3}\right), 64.27\left(4^{\prime} \mathrm{a}-\mathrm{CH}_{2}\right), 70.82\left(\mathrm{C}-1^{\prime \prime}\right), 76.33(\mathrm{C}-8)$, 110.09 (C-12), 111.85 (C-3), 118.16 (C-5), 119.39 (C-14), $122.78\left({\mathrm{C}-5^{\prime}}^{\prime}\right), 135.84$ (C-10), $146.38\left(\mathrm{C}-4^{\prime}\right), 146.48$ (C-11), 
147.90 (C-13), 151.46 (C-4), 160.06 (C-2); HRMS: Calculated for $\mathrm{C}_{25} \mathrm{H}_{32} \mathrm{BrN}_{3} \mathrm{O}_{5}[\mathrm{M}+\mathrm{H}+2]^{+} 536.1604$, found 536.1590 .

2.3.6f 4-((4-((10-Bromodecyloxy)methyl)-1H-1,2,3triazol-1-yl)methyl)-10-methoxy-8,8-dimethyl-7,8-dihydropyrano[3,2-g]chromen-2(6H)-one (25): Yield $=83 \%$; M.p.: $155-156^{\circ} \mathrm{C}$; UV $(\mathrm{MeOH}) \lambda_{\max }: 333 \mathrm{~nm}$; IR $(\mathrm{KBr})$ $\nu_{\max }: 2924.30,2852.88,1711.86,1611.77,1570.57,1456.96$, 1404.47, 1350.70, 1154.42, 1103.84, 964.57, $892.05 \mathrm{~cm}^{-1}$; ${ }^{1} \mathrm{H} \mathrm{NMR}\left(\mathrm{CDCl}_{3}, 400 \mathrm{MHz}\right): \delta 1.24-1.38\left(\mathrm{~m}, 18 \mathrm{H}, 2 \times \mathrm{CH}_{3}\right.$, $\left.\mathrm{H}-3^{\prime \prime}-\mathrm{H}-8^{\prime \prime}\right), 1.52-1.59$ (m, 2H, H-2"), 1.79-1.83 (m, 4H, H-9", H-7), 2.79 (t, 2H, $J=6.8 \mathrm{~Hz}, \mathrm{H}-6), 3.37$ (t, 2H, $J=$ $6.8 \mathrm{~Hz}, \mathrm{H}-10^{\prime \prime}$ ), 3.49 (t, $2 \mathrm{H}, J=6.8 \mathrm{~Hz}, \mathrm{H}-1^{\prime \prime}$ ), 3.89 (s, 3H, $\left.\mathrm{OCH}_{3}\right), 4.59\left(\mathrm{~s}, 2 \mathrm{H}, 4^{\prime} \mathrm{a}-\mathrm{CH}_{2}\right), 5.59\left(\mathrm{~s}, 2 \mathrm{H}, 4 \mathrm{a}-\mathrm{CH}_{2}\right), 5.82$ (s, 1H, H-3), 7.05 (s, 1H, H-5), 7.58 (s, 1H, H-5 ); ${ }^{13} \mathrm{C} \mathrm{NMR}$ $\left(\mathrm{CDCl}_{3}, 100.5 \mathrm{MHz}\right): \delta 22.25$ (C-6), $26.02\left(\mathrm{C}-8^{\prime \prime}\right), 26.86$ $\left(2 \times \mathrm{CH}_{3}\right), 28.09,28.67,29.30,29.35,29.37\left(\mathrm{C}-3^{\prime \prime}, \mathrm{C}-4^{\prime \prime}\right.$, C-5", C-6", C-7"), $29.55\left(\mathrm{C}-2^{\prime \prime}\right), 32.14$ (C-7), 32.75 (C-9"), $34.11\left(\mathrm{C}-10^{\prime \prime}\right), 50.27\left(4 \mathrm{a}-\mathrm{CH}_{2}\right), 61.20\left(\mathrm{OCH}_{3}\right), 64.26\left(4^{\prime} \mathrm{a}\right.$ $\left.-\mathrm{CH}_{2}\right), 71.14\left(\mathrm{C}-1^{\prime \prime}\right), 76.32$ (C-8), $110.10(\mathrm{C}-12), 111.88$ (C-3), 118.17 (C-5), 119.39 (C-14), $122.74\left(\mathrm{C}-5^{\prime}\right), 135.83$ (C-10), 146.38 (C-4'), 146.58 (C-11), 147.88 (C-13), 151.45 (C-4), 160.04 (C-2); HRMS: Calculated for $\mathrm{C}_{29} \mathrm{H}_{40} \mathrm{BrN}_{3} \mathrm{O}_{5}$ $[\mathrm{M}+\mathrm{H}+2]^{+}$592.2230, found 592.2210.

2.3.7 Synthesis of quaternary ammonium compounds $\mathbf{2 6 - 3 1}$

To the solution of bromo- precursor (1g) (20-25) in anhydrous acetonitrile $(40 \mathrm{~mL})$, trimethylamine was added (5 equivalents) and the reaction mixture was stirred under nitrogen at $70^{\circ} \mathrm{C}$ for approximately $72 \mathrm{~h}$. The progress of the reaction was monitored on TLC (methanol:chloroform, 1:4). On completion of the reaction, acetonitrile was evaporated under reduced pressure and the resultant product was then subjected to column chromatography to give the pure quaternary ammonium compound (26-31) in moderate to high yields (65-84\%) as off-white or pale brown solid.

2.3.7a 6-((1-((8,8-Dimethyl-2-oxo-2,6,7,8-tetrahydropyrano[3,2-g]chromen-4-yl)methyl)-1H-1,2,3-triazol4-yl)methoxy)- $N, N, N$-triethylhexan-1-aminium bromide (26): $\quad$ Yield $=82 \%$; M.p.: $107-108^{\circ} \mathrm{C}$; UV $(\mathrm{MeOH}) \lambda_{\max }$ : $335 \mathrm{~nm}$; IR (KBr) v $v_{\max }: 2922.68,2854.28,1725.07,1622.72$, $1567.90,1457.75,1387.54,1327.80,1236.22,1119.14$, 1046.24, $892.06 \mathrm{~cm}^{-1} ;{ }^{1} \mathrm{H}$ NMR $\left(\mathrm{CDCl}_{3}, 400 \mathrm{MHz}\right): \delta$ 1.28-1.38 (m, 21H, $2 \times \mathrm{CH}_{3}, \mathrm{H}-2-\mathrm{H}-4,3 \times \mathrm{CH}_{3}$ of ethyl), $1.52-1.55$ (m, 2H, H-5), 1.79 (t, $\left.2 \mathrm{H}, J=6.1 \mathrm{~Hz}, \mathrm{H}-7^{\prime \prime}\right), 2.81$ (t, 2H, $\left.J=6.1 \mathrm{~Hz}, \mathrm{H}-6^{\prime \prime}\right), 3.23-3.28$ (m, 2H, H-1), 3.35-3.44 (m, $6 \mathrm{H}, 3 \times \mathrm{CH}_{2}$ of ethyl), $3.46(\mathrm{t}, 2 \mathrm{H}, J=6.1 \mathrm{~Hz}, \mathrm{H}-6$ ), $4.56\left(\mathrm{~s}, 2 \mathrm{H}, 4^{\prime} \mathrm{a}-\mathrm{CH}_{2}\right), 5.69$ (s, $\left.1 \mathrm{H}, \mathrm{H}-3^{\prime \prime}\right), 5.88\left(\mathrm{~s}, 2 \mathrm{H}, 4^{\prime \prime} \mathrm{a}\right.$ $-\mathrm{CH}_{2}$ ), 6.64 (s, $\left.1 \mathrm{H}, \mathrm{H}-10^{\prime \prime}\right), 7.49$ (s, 1H, H-5"), 8.14 (s, $\left.1 \mathrm{H}, \mathrm{H}-5^{\prime}\right) ;{ }^{13} \mathrm{C}$ NMR $\left(\mathrm{CDCl}_{3}, 100.5 \mathrm{MHz}\right): \delta 7.85\left(\mathrm{CH}_{3}\right.$ of ethyl), 21.76 (C-2), 21.90 (C-6"), 25.69, 25.80 (C-3, C-4), $26.78\left(2 \times \mathrm{CH}_{3}\right), 28.89(\mathrm{C}-5), 32.19\left(\mathrm{C}-7^{\prime \prime}\right), 49.75\left(4^{\prime \prime} \mathrm{a}-\right.$ $\left.\mathrm{CH}_{2}\right), 53.18\left(\mathrm{CH}_{2}\right.$ of ethyl), $57.26(\mathrm{C}-1), 64.03\left(4^{\prime} \mathrm{a}-\mathrm{CH}_{2}\right)$, 69.88 (C-6), $76.00\left(\mathrm{C}-8^{\prime \prime}\right), 104.57\left(\mathrm{C}-10^{\prime \prime}\right), 110.14\left(\mathrm{C}-12^{\prime \prime}\right)$, $110.29\left(\mathrm{C}-3^{\prime \prime}\right), 118.89\left(\mathrm{C}-14^{\prime \prime}\right), 124.43\left(\mathrm{C}-5^{\prime}\right), 124.69(\mathrm{C}-$ 5"), 145.57 (C-4'), 149.58 (C-11"), 153.39, 158.12 (C-4", C-13"), 161.00 (C-2"); HRMS: Calculated for $\mathrm{C}_{30} \mathrm{H}_{45} \mathrm{~N}_{4} \mathrm{O}_{4}^{+}$ $[\mathrm{M}]^{+}$525.3435, found 525.3447.

2.3.7b 10-((1-((8,8-Dimethyl-2-oxo-2,6,7,8-tetrahydro pyrano[3,2-g]chromen-4-yl)methyl)-1H-1,2,3-triazol4yl)methoxy)-N,N,N-triethyldecan-1-aminium bromide (27): $\quad$ Yield $=84 \%$; M.p.: $109-110^{\circ} \mathrm{C}$; UV $(\mathrm{MeOH}) \lambda_{\max }$ : 201, $335 \mathrm{~nm}$; IR (KBr) $v_{\max }: 2924.85,2855.58,1722.08$, $1622.18,1560.59,1458.15,1388.63,1327.63,1225.93$, $1151.48,1116.75,1045.25,886.74,751.29 \mathrm{~cm}^{-1} ;{ }^{1} \mathrm{H} \mathrm{NMR}$ $\left(\mathrm{CDCl}_{3}, 400 \mathrm{MHz}\right): \delta 1.23-1.37\left(\mathrm{~m}, 29 \mathrm{H}, 2 \times \mathrm{CH}_{3}, \mathrm{H}-2-\right.$ $\mathrm{H}-8,3 \times \mathrm{CH}_{3}$ of ethyl), $1.50-1.57$ (m, 2H, H-9), $1.81(\mathrm{t}, 2 \mathrm{H}$, $\left.J=6.8 \mathrm{~Hz}, \mathrm{H}-7^{\prime \prime}\right), 2.80$ (t, $\left.2 \mathrm{H}, J=6.8 \mathrm{~Hz}, \mathrm{H}-6^{\prime \prime}\right), 3.20-3.24$ (m, 2H, H-1), 3.41-3.50 (m, $8 \mathrm{H}, 3 \times \mathrm{CH}_{2}$ of ethyl, $\mathrm{H}-10$ ), $4.59\left(\mathrm{~s}, 2 \mathrm{H}, 4^{\prime} \mathrm{a}-\mathrm{CH}_{2}\right), 5.71\left(\mathrm{~s}, 2 \mathrm{H}, 4^{\prime \prime} \mathrm{a}-\mathrm{CH}_{2}\right), 5.83(\mathrm{~s}$, $\left.1 \mathrm{H}, \mathrm{H}-3^{\prime \prime}\right), 6.70$ (s, 1H, H-10"), 7.39 (s, 1H, H-5"), 7.72 (s, $\left.1 \mathrm{H}, \mathrm{H}-5^{\prime}\right) ;{ }^{13} \mathrm{C}$ NMR $\left(\mathrm{CDCl}_{3}, 100.5 \mathrm{MHz}\right): \delta 7.92\left(\mathrm{CH}_{3}\right.$ of ethyl), 21.85 (C-2), 21.99 (C-6"), 25.84, 26.25 (C-5, C-6), $26.84\left(2 \times \mathrm{CH}_{3}\right), 28.85,28.91,28.97,29.01(\mathrm{C}-3, \mathrm{C}-4, \mathrm{C}-7$, C-8), 29.40 (C-9), 32.23 (C-7"), $50.13\left(4^{\prime \prime} \mathrm{a}-\mathrm{CH}_{2}\right), 53.32$ $\left(\mathrm{CH}_{2}\right.$ of ethyl), $57.38(\mathrm{C}-1), 64.16\left(4^{\prime} \mathrm{a}-\mathrm{CH}_{2}\right), 70.82(\mathrm{C}-10)$, $76.11\left(\mathrm{C}-8^{\prime \prime}\right), 104.73\left(\mathrm{C}-10^{\prime \prime}\right), 109.96\left(\mathrm{C}-12^{\prime \prime}\right), 111.23(\mathrm{C}-$ $\left.3^{\prime \prime}\right), 118.89\left(\mathrm{C}-14^{\prime \prime}\right), 123.44\left(\mathrm{C}-5^{\prime}\right), 124.59\left(\mathrm{C}-5^{\prime \prime}\right), 146.24$ $\left(\mathrm{C}-4^{\prime}\right), 148.53\left(\mathrm{C}-11^{\prime \prime}\right), 153.61,158.34\left(\mathrm{C}-4^{\prime \prime}, \mathrm{C}-13^{\prime \prime}\right)$, 160.69 (C-2"); HRMS: Calculated for $\mathrm{C}_{34} \mathrm{H}_{53} \mathrm{~N}_{4} \mathrm{O}_{4}^{+}[\mathrm{M}]^{+}$ 581.4061, found 581.4061.

2.3.7c $\quad N, N, N$-Triethyl-6-((1-((10-hydroxy-8,8-dimethyl-2-oxo-2,6,7,8-tetrahydropyrano[3,2-g]chromen-4yl)methyl)-1H-1,2,3-triazol-4-yl)methoxy)hexan-1-aminium bromide (28): Yield $=70 \%$; M.p.: $114-115^{\circ} \mathrm{C}$; UV $(\mathrm{MeOH}) \lambda_{\max }: 265$ and $335 \mathrm{~nm}$; IR (KBr) $v_{\max }: 2929.67$, $2860.54,1720.53,1616.63,1571.77,1453.32,1403.22$, 1348.81, 11158.81, 1112.40, 1043.88, $754.04 \mathrm{~cm}^{-1} ;{ }^{1} \mathrm{H}$ NMR (DMSO- $\left.d_{6}, 400 \mathrm{MHz}\right): \delta 1.13(\mathrm{t}, 9 \mathrm{H}, J=6.8 \mathrm{~Hz}, 3$ $\times \mathrm{CH}_{3}$ of ethyl), $1.25-1.32\left(\mathrm{~m}, 10 \mathrm{H}, 2 \times \mathrm{CH}_{3}, \mathrm{H}-3-\mathrm{H}-4\right)$, $1.47-1.52(\mathrm{~m}, 4 \mathrm{H}, \mathrm{H}-2$ \& H-5), $1.80(\mathrm{t}, 2 \mathrm{H}, J=6.8 \mathrm{~Hz}, \mathrm{H}-$ $\left.7^{\prime \prime}\right), 2.78$ (t, $\left.2 \mathrm{H}, J=6.8 \mathrm{~Hz}, \mathrm{H}-6^{\prime \prime}\right), 3.05-3.09$ (m, 2H, H-1), $3.17-3.23\left(\mathrm{q}, 6 \mathrm{H}, J=6.8 \mathrm{~Hz}, 3 \times \mathrm{CH}_{2}\right.$ of ethyl), $3.42(\mathrm{t}, 2 \mathrm{H}$, $J=6.8 \mathrm{~Hz}, \mathrm{H}-6), 4.51$ (s, 2H, 4' $\left.\mathrm{a}-\mathrm{CH}_{2}\right), 5.42\left(\mathrm{~s}, 1 \mathrm{H}, \mathrm{H}-3^{\prime \prime}\right)$, 5.88 (s, 2H, 4"a-CH $\left.\mathrm{CH}_{2}\right), 7.14$ (s, $\left.1 \mathrm{H}, \mathrm{H}-5^{\prime \prime}\right), 8.25$ (s, $1 \mathrm{H}, \mathrm{H}-$ $\left.5^{\prime}\right), 9.24(\mathrm{~s}, 1 \mathrm{H}, \mathrm{OH}) ;{ }^{13} \mathrm{C}$ NMR (DMSO- $\left.d_{6}, 100.5 \mathrm{MHz}\right): \delta$ $7.18\left(\mathrm{CH}_{3}\right.$ of ethyl), 20.86 (C-2), 21.67 (C-6"), 25.22, 25.57 (C-3, C-4), $26.56\left(2 \times \mathrm{CH}_{3}\right), 28.85(\mathrm{C}-5), 31.80\left(\mathrm{C}-7^{\prime \prime}\right)$, $49.14\left(4^{\prime \prime} \mathrm{a}-\mathrm{CH}_{2}\right), 51.93\left(\mathrm{CH}_{2}\right.$ of ethyl), $55.90(\mathrm{C}-1), 63.14$ $\left(4^{\prime} \mathrm{a}-\mathrm{CH}_{2}\right), 69.34(\mathrm{C}-6), 75.78\left(\mathrm{C}-8^{\prime \prime}\right), 109.47\left(\mathrm{C}-12^{\prime \prime}\right)$, $109.93\left(\mathrm{C}-3^{\prime \prime}\right), 114.34\left(\mathrm{C}-5^{\prime \prime}\right), 118.17\left(\mathrm{C}-14^{\prime \prime}\right), 125.12(\mathrm{C}-$ 5'), 132.95 (C-10"), 140.95 (C-4'), $144.64\left(\mathrm{C}-11^{\prime \prime}\right), 146.11$, 151.01 (C-4", C-13"), 159.86 (C-2"); HRMS: Calculated for $\mathrm{C}_{30} \mathrm{H}_{45} \mathrm{~N}_{4} \mathrm{O}_{5}^{+}[\mathrm{M}]^{+}$541.3384, found 541.3357. 
2.3.7d N,N,N-Triethyl-10-((1-((10-hydroxy-8,8-dimethyl-2-oxo-2,6,7,8-tetrahydropyrano[3,2-g]chromen4-yl)methyl)-1H-1,2,3-triazol-4-yl)methoxy)decan-1aminium bromide (29): Yield $=64 \%$; M.p.: $157-158^{\circ} \mathrm{C}$; $\mathrm{UV}(\mathrm{MeOH}) \lambda_{\max }: 264$ and $334 \mathrm{~nm}$; IR (KBr) $\nu_{\max }: 1715.26$, $1620.99,1577.35,1459.70,1403.77,1353.77,1250.34$, 1158.12, 1097.11, 1039.38, 799.41, $749.97 \mathrm{~cm}^{-1} ;{ }^{1} \mathrm{H} \mathrm{NMR}$ (DMSO- $\left.d_{6}, 400 \mathrm{MHz}\right): \delta 1.14$ (t, $9 \mathrm{H}, J=6.8 \mathrm{~Hz}, 3 \times \mathrm{CH}_{3}$ of ethyl), 1.22-1.32 (m, $\left.18 \mathrm{H}, 2 \times \mathrm{CH}_{3}, \mathrm{H}-3-\mathrm{H}-8\right), 1.45-$ 1.53 (m, 4H, H-2 \& H-9), 1.81 (t, 2H, $\left.J=6.8 \mathrm{~Hz}, \mathrm{H}-7^{\prime \prime}\right)$, $2.78\left(\mathrm{t}, 2 \mathrm{H}, J=6.8 \mathrm{~Hz}, \mathrm{H}-6^{\prime \prime}\right), 3.05-3.10(\mathrm{~m}, 2 \mathrm{H}, \mathrm{H}-1)$, $3.17-3.23$ (q, $6 \mathrm{H}, J=6.8 \mathrm{~Hz}, 3 \times \mathrm{CH}_{2}$ of ethyl), 3.40 (t, $2 \mathrm{H}, J=6.8 \mathrm{~Hz}, \mathrm{H}-10), 4.50\left(\mathrm{~s}, 2 \mathrm{H}, 4^{\prime} \mathrm{a}-\mathrm{CH}_{2}\right), 5.45(\mathrm{~s}, 1 \mathrm{H}$, H-3"), 5.87 (s, 2H, 4" a-CH ${ }_{2}$ ), 7.13 (s, $\left.1 \mathrm{H}, \mathrm{H}-5^{\prime \prime}\right), 8.23$ (s, $\left.1 \mathrm{H}, \mathrm{H}-5^{\prime}\right), 9.19(\mathrm{~s}, 1 \mathrm{H}, \mathrm{OH}) ;{ }^{13} \mathrm{C}$ NMR (DMSO- $d_{6}, 100.5$ $\mathrm{MHz}): \delta 7.19\left(\mathrm{CH}_{3}\right.$ of ethyl), $20.93(\mathrm{C}-2), 21.68\left(\mathrm{C}-6^{\prime \prime}\right)$, 25.63, 25.79 (C-5, C-6), $26.57\left(2 \times \mathrm{CH}_{3}\right), 28.49,28.77$, 28.86 (C-3, C-4, C-7, C-8), 29.08 (C-9), 31.81 (C-7"), 49.17 $\left(4^{\prime \prime} \mathrm{a}-\mathrm{CH}_{2}\right), 51.95\left(\mathrm{CH}_{2}\right.$ of ethyl), $55.99(\mathrm{C}-1), 63.15$ $\left(4^{\prime} \mathrm{a}-\mathrm{CH}_{2}\right), 69.49(\mathrm{C}-10), 75.79\left(\mathrm{C}-8^{\prime \prime}\right), 109.60\left(\mathrm{C}-3^{\prime \prime}\right)$, 110.00 (C-12"), 114.35 (C-5"), 118.17 (C-14"), 125.11 (C-5'), $132.94\left(\mathrm{C}-10^{\prime \prime}\right), 140.96\left(\mathrm{C}-4^{\prime}\right), 144.69$ (C-11"), 146.08, 150.93 (C-4", C-13"), 159.94 (C-2"); HRMS: Calculated for $\mathrm{C}_{34} \mathrm{H}_{53} \mathrm{~N}_{4} \mathrm{O}_{5}^{+}[\mathrm{M}]^{+}$597.4010, found 597.4019.

2.3.7e $\quad N, N, N$-Triethyl-6-((1-((10-methoxy-8,8-dimethyl-2-oxo-2,6,7,8-tetrahydropyrano[3,2-g]chromen4-yl)methyl)-1H-1,2,3-triazol-4-yl)methoxy)hexan-1aminium bromide (30): Yield $=80 \%$; M.p.: $91-92^{\circ} \mathrm{C}$; UV (MeOH) $\lambda_{\max }: 333 \mathrm{~nm}$; IR (KBr) $\nu_{\max }: 2927.74$, $2858.43,1720.27,1613.09,1568.37,1455.48,1398.18$, $1350.58,1222.09,1156.98,1111.35,1047.05,1013.76$, $889.08 \mathrm{~cm}^{-1} ;{ }^{1} \mathrm{H}$ NMR $\left(\mathrm{CDCl}_{3}, 400 \mathrm{MHz}\right): \delta 1.31-1.38(\mathrm{~m}$, $21 \mathrm{H}, 2 \times \mathrm{CH}_{3}, \mathrm{H}-2-\mathrm{H}-4,3 \times \mathrm{CH}_{3}$ of ethyl), $1.55-1.58(\mathrm{~m}$, $2 \mathrm{H}, \mathrm{H}-5), 1.83$ (t, 2H, $\left.J=6.8 \mathrm{~Hz}, \mathrm{H}-7^{\prime \prime}\right), 2.85$ (t, 2H, $J=$ $\left.6.8 \mathrm{~Hz}, \mathrm{H}-6^{\prime \prime}\right), 3.27-3.31$ (m, 2H, H-1), 3.36-3.41 (m, 6H, 3 $\times \mathrm{CH}_{2}$ of ethyl), $3.49(\mathrm{t}, 2 \mathrm{H}, J=6.1 \mathrm{~Hz}, \mathrm{H}-6), 3.88(\mathrm{~s}, 3 \mathrm{H}$, $\left.\mathrm{OCH}_{3}\right), 4.60$ (s, 2H, 4'a-CH $), 5.76\left(\mathrm{~s}, 1 \mathrm{H}, \mathrm{H}-3^{\prime \prime}\right), 5.89$ (s, $2 \mathrm{H}, 4^{\prime \prime} \mathrm{a}-\mathrm{CH}_{2}$ ), 7.27 (s, $\left.1 \mathrm{H}, \mathrm{H}-5^{\prime \prime}\right), 8.19$ (s, $\left.1 \mathrm{H}, \mathrm{H}-5^{\prime}\right) ;{ }^{13} \mathrm{C}$ NMR $\left(\mathrm{CDCl}_{3}, 100.5 \mathrm{MHz}\right): \delta 7.87\left(\mathrm{CH}_{3}\right.$ of ethyl), $21.81(\mathrm{C}-$ 2), $22.19\left(\mathrm{C}-6^{\prime \prime}\right), 25.77,25.82(\mathrm{C}-3, \mathrm{C}-4), 26.84\left(2 \times \mathrm{CH}_{3}\right)$, 28.92 (C-5), $32.15\left(\mathrm{C}-7^{\prime \prime}\right), 49.79\left(4^{\prime \prime} \mathrm{a}-\mathrm{CH}_{2}\right), 53.21\left(\mathrm{CH}_{2}\right.$ of ethyl), $57.32(\mathrm{C}-1), 61.10\left(\mathrm{OCH}_{3}\right), 64.10\left(4^{\prime} \mathrm{a}-\mathrm{CH}_{2}\right)$, 69.86 (C-6), $76.25\left(\mathrm{C}-8^{\prime \prime}\right), 110.33\left(\mathrm{C}-12^{\prime \prime}\right), 110.60\left(\mathrm{C}-3^{\prime \prime}\right)$, $118.76\left(\mathrm{C}-5^{\prime \prime}\right), 119.41\left(\mathrm{C}-14^{\prime \prime}\right), 124.48\left(\mathrm{C}-5^{\prime}\right), 135.50$ (C$\left.10^{\prime \prime}\right), 145.72$ (C-4'), 146.07 (C-11"), 149.83, 151.24 (C-4", C-13"), $160.64\left(\mathrm{C}-2^{\prime \prime}\right)$; HRMS: Calculated for $\mathrm{C}_{31} \mathrm{H}_{47} \mathrm{~N}_{4} \mathrm{O}_{5}^{+}$ $[\mathrm{M}]^{+}$555.3541, found 555.3548.

2.3.7f N,N,N-Triethyl-10-((1-((10-methoxy-8,8-dimethyl-2-oxo-2,6,7,8-tetrahydropyrano[3,2-g]chromen4-yl)methyl)-1H-1,2,3-triazol-4-yl)methoxy)decan-1aminium bromide (31): Yield $=83 \%$; M.p.: $98-99^{\circ} \mathrm{C}$; UV $(\mathrm{MeOH}) \lambda_{\max }: 208,260,333 \mathrm{~nm}$; IR $(\mathrm{KBr}) \nu_{\max }$ : $1722.00,1613.62,1572.28,1459.01,1353.04,1112.00$, 1047.25, 886.82 $\mathrm{cm}^{-1} ;{ }^{1} \mathrm{H}$ NMR $\left(\mathrm{CDCl}_{3}, 400 \mathrm{MHz}\right): \delta$ 1.22-1.37 (m, 29H, $2 \times \mathrm{CH}_{3}, \mathrm{H}-2-\mathrm{H}-8,3 \times \mathrm{CH}_{3}$ of ethyl), $1.52-1.55(\mathrm{~m}, 2 \mathrm{H}, \mathrm{H}-9), 1.82\left(\mathrm{t}, 2 \mathrm{H}, J=6.8 \mathrm{~Hz}, \mathrm{H}-7^{\prime \prime}\right)$, $2.81\left(\mathrm{t}, 2 \mathrm{H}, J=6.8 \mathrm{~Hz}, \mathrm{H}-6^{\prime \prime}\right), 3.21-3.25(\mathrm{~m}, 2 \mathrm{H}, \mathrm{H}-1)$, 3.43-3.48 (m, $8 \mathrm{H}, 3 \times \mathrm{CH}_{2}$ of ethyl, $\left.\mathrm{H}-10\right), 3.88(\mathrm{~s}, 3 \mathrm{H}$, $\left.\mathrm{OCH}_{3}\right), 4.59$ (s, $\left.2 \mathrm{H}, 4^{\prime} \mathrm{a}-\mathrm{CH}_{2}\right), 5.73\left(\mathrm{~s}, 2 \mathrm{H}, 4^{\prime \prime} \mathrm{a}-\mathrm{CH}_{2}\right)$, 5.83 (s, 1H, H-3"), 7.18 (s, 1H, H-5"), 7.75 (s, 1H, H-5'); ${ }^{13} \mathrm{C}$ NMR $\left(\mathrm{CDCl}_{3}, 100.5 \mathrm{MHz}\right): \delta 7.90\left(\mathrm{CH}_{3}\right.$ of ethyl), 21.82 (C-2), 22.17 (C-6"), 25.81, 26.20 (C-5, C-6), 26.82 $\left(2 \times \mathrm{CH}_{3}\right), 28.81,28.88,28.94,28.98$ (C-3, C-4, C-7, C-8), 29.37 (C-9), $32.11\left(\mathrm{C}-7^{\prime \prime}\right), 50.06\left(4^{\prime \prime} \mathrm{a}-\mathrm{CH}_{2}\right), 53.30\left(\mathrm{CH}_{2}\right.$ of ethyl), $57.38(\mathrm{C}-1), 61.10\left(\mathrm{OCH}_{3}\right), 64.10\left(4^{\prime} \mathrm{a}-\mathrm{CH}_{2}\right), 70.80$ (C-10), $76.30\left(\mathrm{C}-8^{\prime \prime}\right), 110.18\left(\mathrm{C}-12^{\prime \prime}\right), 111.19\left(\mathrm{C}-3^{\prime \prime}\right), 118.57$ (C-5"), $119.45\left(\mathrm{C}-14^{\prime \prime}\right), 123.54\left(\mathrm{C}-5^{\prime}\right), 135.61\left(\mathrm{C}-10^{\prime \prime}\right)$, 146.07, 146.14 (C-4', C-11"), 148.90, $151.23\left(\mathrm{C}-4^{\prime \prime}, \mathrm{C}-13^{\prime \prime}\right)$, $160.31\left(\mathrm{C}-2^{\prime \prime}\right)$; HRMS: Calculated for $\mathrm{C}_{35} \mathrm{H}_{55} \mathrm{~N}_{4} \mathrm{O}_{5}^{+}[\mathrm{M}]^{+}$ 611.4167, found 611.4157 .

\subsection{Biology}

\subsubsection{Pathogens}

Various pathogenic strains of bacteria, namely, B. cereus (MTCC 430), S. aureus (MTCC 740), E. coli (MTCC 1586), $P$. aeruginosa (MTCC 741) were procured from Institute of Microbial Technology, Chandigarh (India).

\subsubsection{Materials}

Mueller-Hinton agar, Muller-Hinton broth, Nutrient broth, sterile Whatman paper discs $(6 \mathrm{~mm})$, Gentamicin, Triton X-100 were procured from Hi-Media, Mumbai, India. Iodonitrotetrazolium chloride (INT), and DMSO were purchased from Sigma-Aldrich Chemicals, USA.

\subsubsection{Antibacterial activity assay}

2.4.3a Zone of Inhibition: The inhibitory potency of synthesized compounds on bacterial growth was estimated, using Kirby-Bauer disc diffusion test with some minor modifications. ${ }^{20,21} 250 \mu \mathrm{g} /$ disc concentration of the samples were impregnated on a $6 \mathrm{~mm}$, sterile Whatman paper disc. The targeted test organisms were seeded before the sterile disc placed in the respective grid of each Mueller-Hinton agar plates. It was incubated at $37^{\circ} \mathrm{C}$ for overnight incubation. Gentamicin and solvent were used in the assay as positive and negative controls respectively. Himedia HiAntibiotic ZoneScale was used to measure the zone of inhibition. The experiment was carried out in triplicates.

\subsection{3b Minimum Inhibitory Concentration (MIC)}

Assay: Minimum inhibitory concentration assay was performed to quantitative evaluation of antibacterial actitivity by estimating the MIC of the compounds. ${ }^{20,21}$ The bacterial strains were cultured overnight at $37^{\circ} \mathrm{C}$ in nutrient broth and used as an inoculum. The wells of ELISA plate with various dilutions of the compounds $(1-0.0001 \mathrm{mg} / \mathrm{mL})$ were treated with $50 \mu \mathrm{L}$ of inoculums $\left(\mathrm{OD}_{600}=0.4-0.6\right)$ of the relevant 
culture and incubated at $37^{\circ} \mathrm{C}$ for overnight. The absorbance at $600 \mathrm{~nm}$ was measured and using gentamicin and solvent as positive and negative controls, respectively. As an indicator of bacterial growth, $50 \mu \mathrm{L}$ of $0.25 \mathrm{mg} / \mathrm{mL}$ iodonitrotetrazolium chloride (INT) was added to the wells and incubated at $37^{\circ} \mathrm{C}$ for $30 \mathrm{~min}$. The significant intensity of red colour formation in ELISA microtiter plate indicated the pervasiveness of live bacterial cells, while clear solution signified the suppression of bacterial growth. All the assays were performed in triplicate.

2.4.3c Haemolytic assay: Haemolysis assay was performed to check the toxicity of active compounds against the human red blood cells (hRBC). ${ }^{22,23}$ Fresh hRBC washed and centrifuged with $10 \mathrm{mM}$ phosphate buffer saline (PBS) thrice. To make 4\% (v/v) solution, hRBC was suspended in PBS (pH 7.4). A $100 \mu \mathrm{L}$ of cell suspension, added to each well of ELISA plate along with $100 \mu \mathrm{L}$ of different concentration of compounds, were incubated at $37^{\circ} \mathrm{C}$ for $1 \mathrm{~h}$ and centrifuged at $1000 \mathrm{~g}$ for $10 \mathrm{~min} .100 \mu \mathrm{L}$ aliquots of supernatant were transferred to fresh ELISA plate and took to absorbance at $540 \mathrm{~nm}$ using ELISA plate reader (Bio-Teck Instruments, Inc.). The absorbance of hRBC treated with $0.1 \%$ Triton $\mathrm{X}-100$ and $1 \mathrm{X}$ PBS was taken as positive and negative controls, respectively. To calculate the haemolysis percentage used following formula:

$$
\text { Haemolysis Percentage }=\left(\frac{\left(O D_{540 \mathrm{~nm}} \text { of Sample }-O D_{540 \mathrm{~nm}} \text { of PBS }\right)}{\left(O D_{540 \mathrm{~nm}} \text { of } 0.1 \% \text { Triton } X-100-O D_{540 \mathrm{~nm}} \text { of PBS }\right)}\right) \times 100
$$

\section{Results and Discussion}

\subsection{Chemistry}

A series of novel quaternary ammonium derivatives 1,2,3-triazolylpyranochromen-2-ones (26-31) were synthesized by the reaction of their corresponding bromoprecursors (20-25) with an excess of triethylamine in anhydrous acetonitrile under refluxing conditions (Scheme 1). ${ }^{8}$ The desired bromo-precursors of quaternary ammonium compounds (20-25) in turn were obtained via Click coupling reaction ${ }^{24}$ between the 4-(azidomethyl)-8,8-dimethyl-7,8-dihydropyrano[3,2-g] chromen-2(6H)-ones (15-17) with the corresponding mono bromo alkynes i.e., 1-bromo-6-(prop-2-yn1-yloxy)hexane (18)/1-bromo-10-(prop-2-yn-1-yloxy) decane (19). The azido compounds 15-17 were synthesized from the 4-(chloromethyl) derivatives of pyranochromen-2-one (12-14) by using sodium azide. As the product (15-17) and the starting material (1214) has nearly an identical retention factor $\left(R_{f}\right)$ in the methanol : chloroform (1:49) system, the appearance of the azide peak at $2100 \mathrm{~cm}^{-1}$ in IR spectrum of product confirmed the conversion of chloro group into azide group. The structure of azido product (15-17) was further confirmed by ${ }^{1} \mathrm{H}$ NMR spectroscopy i.e., on substituting the chloro with the azide group the signal for neighbouring methylene protons shifted from $\delta 4.57$ to $4.46 \mathrm{ppm}$. In ${ }^{13} \mathrm{C} \mathrm{NMR}$, a shift from $\delta 41$ to $51 \mathrm{ppm}$ was observed for the corresponding methylene carbon. The synthesis of compounds $\mathbf{1 2 - 1 4}$ was achieved by first reacting the resorcinol (8)/pyrogallol (9) with 2-methylbuta-1,3-diene (isoprene) in the presence of orthophosphoric acid using xylene as a solvent to get 2,2-dimethylchroman-7-ol (10)/2,2-dimethylchroman-7, 8-diol (11). ${ }^{17}$ Self-condensation of isoprene in this reaction leads to the loss of yield of the desired product, which was minimized by slow addition of isoprene to a stirred solution of resorcinol $(\mathbf{8}) /$ pyrogallol (9) in xylene and orthophosphoric acid. Compound 12/13 was then synthesized in quantitative yield by Pechmann condensation of compound $\mathbf{1 0 / 1 1}$ with 4-chloroethyl acetoacetate in the presence of sulphuric acid. ${ }^{18}$ The compound 14 in turn was synthesized by methylation of compound $\mathbf{1 3}$ using methyl iodide in the presence of potassium carbonate (Scheme 1).

The mono bromo alkynes $(\mathbf{1 8}, \mathbf{1 9})$ were synthesized by alkylation reaction of propargyl alcohol with 1,6- or 1,10-dibromoalkane in the presence of sodium hydroxide as a base. The reaction was carried under phase transfer conditions using TBAI (tetrabutylammonium iodide) as a catalyst (Scheme 1). Among all the synthesized compounds (10-31), the compounds 13-17 and 20-31 are new and reported for the first time and characterized by IR, UV, ${ }^{1} \mathrm{H}$ NMR, ${ }^{13} \mathrm{C}$ NMR, ${ }^{2} \mathrm{D}$ NMR, and mass spectroscopy (Figures S1-S22 in Supplementary Information).

The triazolyl ring proton $\left(\mathrm{H}-5^{\prime}\right)$ in all the quaternary ammonium derivatives (26-31) and their bromoprecursors (20-25) appeared most deshielded (7.56-8.25 ppm) and as a singlet in proton NMR The corresponding carbon $\left(\mathrm{C}-5^{\prime}\right)$ appeared in the range 122.18-124.43 ppm slightly more upfield than C-5 (bromoprecursors) or C-5" (QACs) (124.16-124.69) (Figures S20 and S21, in Supplementary Information). The ${ }^{1} \mathrm{H}-{ }^{13} \mathrm{C}$ correlation spectra of compound 21 (Figure S20), reveals that the $\mathrm{H}-10$ appeared deshielded in region (6.64-6.72 ppm) as compared to H-3 (5.69-5.83 ppm) in proton NMR however a reverse trend observed for the corresponding carbon (C-10) in ${ }^{13} \mathrm{C}$ NMR. Furthermore, it has also 


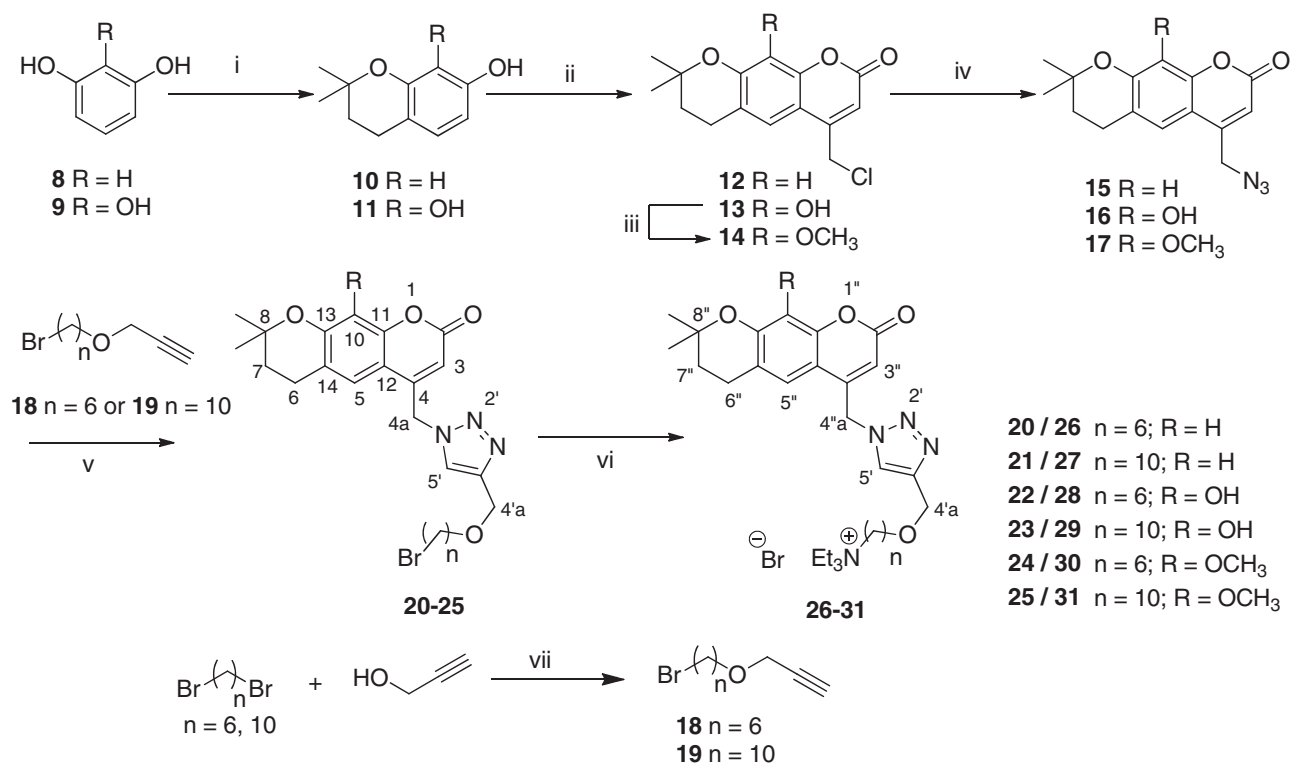

Scheme 1. Reagents and conditions: (i) Isoprene, $\mathrm{H}_{3} \mathrm{PO}_{4}$, xylene, $15 \mathrm{~h}, 25^{\circ} \mathrm{C}$; (ii) 4chloroethyl acetoacetate, conc. $\mathrm{H}_{2} \mathrm{SO}_{4}, 12 \mathrm{~h}, 25-30^{\circ} \mathrm{C}$; (iii) $\mathrm{CH}_{3} \mathrm{I}, \mathrm{K}_{2} \mathrm{CO}_{3}$, acetone, $24 \mathrm{~h}, 25-$ $30^{\circ} \mathrm{C}$; (iv) $\mathrm{NaN}_{3}$, acetone, $18 \mathrm{~h}, 40^{\circ} \mathrm{C}$; (v) $\mathrm{CuSO}_{4} \cdot 5 \mathrm{H}_{2} \mathrm{O}$, sodium ascorbate, THF: $\mathrm{H}_{2} \mathrm{O}(3: 1$ ), $20 \mathrm{~h}, 50^{\circ} \mathrm{C}$; (vi) $\mathrm{NEt}_{3}$, acetonitrile, $90 \mathrm{~h}, 70^{\circ} \mathrm{C}$; (vii) $\mathrm{NaOH}, \mathrm{TBAI}, \mathrm{H}_{2} \mathrm{O}, 50^{\circ} \mathrm{C}$.

been established from a HETCOR spectrum that methylene group flanked between pyrano chromenone and triazole i.e., (4a or $4^{\prime \prime}$ a) appeared at higher $\delta$ than the methylene group (4'a) flanked between oxygen and triazole in proton NMR and the reverse chemical shift order was observed for their corresponding carbons. Also, among the methylene groups at $6^{\text {th }}$ and $7^{\text {th }}$ position of pyrano chromenone moiety, the proton of latter appeared (H-7) more shielded ( $\delta$ 1.77-1.82) in proton NMR, although the corresponding carbon C-7 appeared deshielded than C-6. For the quaternary ammonium derivatives, the two characteristic peaks observed as multiplet in region 3.05$3.31 \mathrm{ppm}$ and 3.17-3.50 ppm integrating for two and six protons correspond to methylene protons of alkyl chain (H-1) and methylene protons of triethyl ammonium moiety, respectively. ${ }^{1} \mathrm{H}-{ }^{13} \mathrm{C}$ correlation spectra of compound 29 (Figure S22 in Supplementary Information), reveals that $\mathrm{C}-1$ appeared deshielded than Cs of methylene protons of triethyl ammonium moiety. The quaternization was further supported by the most upfield carbon observed in region 7.18-7.92 $\mathrm{ppm}$ in ${ }^{13} \mathrm{C}$ NMR spectra of compounds corresponds to the Cs of methyl groups of triethyl ammonium moiety. The ${ }^{1} \mathrm{H}$ and ${ }^{13} \mathrm{C}$ NMR chemical shift values of all the remaining protons and carbons of quaternary ammonium derivatives were also assigned and the spectral data is given in the experimental section (Supplementary Information)

\subsection{Antibacterial activity}

The antibacterial activity screening of all the synthesized quaternary ammonium derivatives (26-31) and their bromo-precursors (20-25) was carried out against four pathogenic bacterial strains i.e., two Grampositives Bacillus cereus and Staphylococcus aureus and two Gram-negatives Pseudomonas aeruginosa and Escherichia coli by disc diffusion assay performed at a concentration of $250 \mu \mathrm{g} /$ disc (Table 1). ${ }^{11,20,21}$ The screening results revealed that three of the six quaternary ammonium compounds (26-31), i.e., 27, 29, and 31 having a longer alkyl moiety $(\mathrm{n}=10)$, exhibited excellent to moderate activity against two gram-positive bacteria (B. cereus and $S$. aureus) and a gram-negative bacterium ( $P$. aeruginosa). All of these compounds developed a zone of inhibition (ZI) equal to or greater than $12 \mathrm{~mm}$. However, the quaternary ammonium derivatives having shorter alkyl chain $(\mathrm{n}=6)(\mathbf{2 6}$, 28, and 30) were observed to possess relatively low antibacterial potential, thus suggesting that larger alkyl chain spacer is favourable for the antibacterial activity. However, none of the quaternary ammonium compounds were found to be active against the gram-negative bacterium viz., E. coli. Also, the bromo-precursors too were found to be inactive against all of the studied bacterial pathogens at the concentration studied (250 $\mu \mathrm{g} /$ disc) (Table 1). The compound 27 developed the maximum ZI of 17, 23, and $24 \mathrm{~mm}$ against $S$. aureus, 
Table 1. Zone of inhibition of quaternary compounds (26-31) against pathogenic bacterial strains using gentamicin as positive controls.

\begin{tabular}{lccccc}
\hline & & \multicolumn{2}{c}{ Zone of inhibition (mm) } \\
S. No. & Compound & Staphylococcus aureus & Bacillus cereus & Pseudomonas aeruginosa & Escherichia coli \\
\hline 1. & 26 & 12 & 12 & 13 & 10 \\
2. & 27 & 17 & 23 & 24 & 10 \\
3. & 28 & - & - & 11 & - \\
4. & 29 & 12 & 13 & 12 & 10 \\
5. & 30 & - & 10 & 10 & - \\
6. & 31 & 28 & 22 & 22 & 28 \\
7. & Gentamicin & 28 & 30 & \\
\hline
\end{tabular}

${ }^{\mathrm{a}}$ Conc. of the compound: $250 \mu \mathrm{g} /$ disc.

$-:$ No activity at the tested concentration.

Compounds 20-25 did not exhibit any noticeable antibacterial activity.

All the experiments were carried out in triplicate.

Table 2. Minimum inhibitory concentration of shortlisted compounds 26, 27, 29, 31 and their precursors 20, 21, 23, 25 against pathogenic bacterial test strains.

\begin{tabular}{lcccc}
\hline S. No. & Compound & Staphylococcus aureus & $\begin{array}{c}\text { MIC }(\mu \mathrm{g} / \mathrm{ml}) \\
\text { Bacillus cereus }\end{array}$ & Pseudomonas aeruginosa \\
\hline 1. & 20 & $>250$ & $>250$ & $>250$ \\
2. & 21 & 200 & 200 & 200 \\
3. & 23 & $>250$ & $>250$ & $>250$ \\
4. & 25 & 188 & $>250$ & $>250$ \\
5. & 26 & 12 & 125 & 188 \\
6. & 27 & 90 & 6 & 8 \\
7. & 29 & 55 & 65 & 115 \\
8. & 31 & & 40 & 45 \\
\hline
\end{tabular}

B. cereus, and $P$. aeruginosa, respectively, and was found to be the most active compound among all the quaternary ammonium ions having $\mathrm{n}=10$.

In order to get an in-depth understanding of the factors that affect the growth inhibition process of various bacterial strains, minimum inhibitory concentration (MIC) was evaluated using a microbroth dilution assay. ${ }^{8,11,20,21}$ Table 2 shows the MIC values of the active compounds along with their precursors. Compound 27, which developed the maximum zone of inhibition against $S$. aureus, B. cereus, and $P$. aeruginosa inhibited the growth of these pathogenic bacterial strains at a concentration of 12,6 , and $8 \mu \mathrm{g} / \mathrm{mL}$, respectively. It has been noticed that the hydroxy derivative (29) of compound 27 exhibit lesser antibacterial activity i.e., MIC value 90,65 , and $115 \mu \mathrm{g} / \mathrm{mL}$ for $S$. aureus, B. cereus, and $P$. aeruginosa, respectively. However, the corresponding methoxy derivative (31) have OMe at C10 position, exhibited improved antibacterial activity with a MIC of 55,40 , and $45 \mu \mathrm{g} / \mathrm{mL}$ against $S$. aureus, $B$. cereus and $P$. aeruginosa, respectively.

These results suggest that both the length of spacer (n) and substituents $(\mathrm{H} / \mathrm{OH} / \mathrm{OMe})$ at the $\mathrm{C}-10$ position of pyranochromen-2-one led to the variation in the lipophilicity of the compounds and this in turn affect the antibacterial activity. The antibacterial activity is favoured by increasing the length of the spacer (n) from 6 to 10 . The antibacterial activity order for varying substitution at 10 position of pyranochromen-2-one is $\mathrm{H}$ $>\mathrm{OMe}>\mathrm{OH}$.

\subsection{Cytotoxicity study}

The four active ammonium compounds, i.e., 26, 27, 29, and $\mathbf{3 1}$ were further investigated for their cytotoxicity on the viability of human erythrocytes by haemolytic assay at various multiples of their MIC values (Figure $3)^{22,23}$ Among the quaternary ammonium compounds having longer spacer $(\mathbf{2 7}, \mathbf{2 9}$ and $\mathbf{3 1})$, the compound 29 exhibits the least toxicity as it exhibited $13 \%$ haemolysis at $50 \times$ of their MIC $(65 \mu \mathrm{g} / \mathrm{mL})$ for B. cereus. However, the compounds $\mathbf{2 7}$ and $\mathbf{3 1}$ were observed to cause $20 \%$ and $24 \%$ lysis of the cells at $40 \times$ and $20 \times$, respectively of their MIC $(6 \mu \mathrm{g} / \mathrm{mL}$ and $40 \mu \mathrm{g} / \mathrm{mL})$ for $B$. cereus. For compound $\mathbf{2 6}$ at the $30 \times \mathrm{MIC}(125 \mu \mathrm{g} / \mathrm{mL})$ for B. cereus, $29 \%$ cells were lysed. 


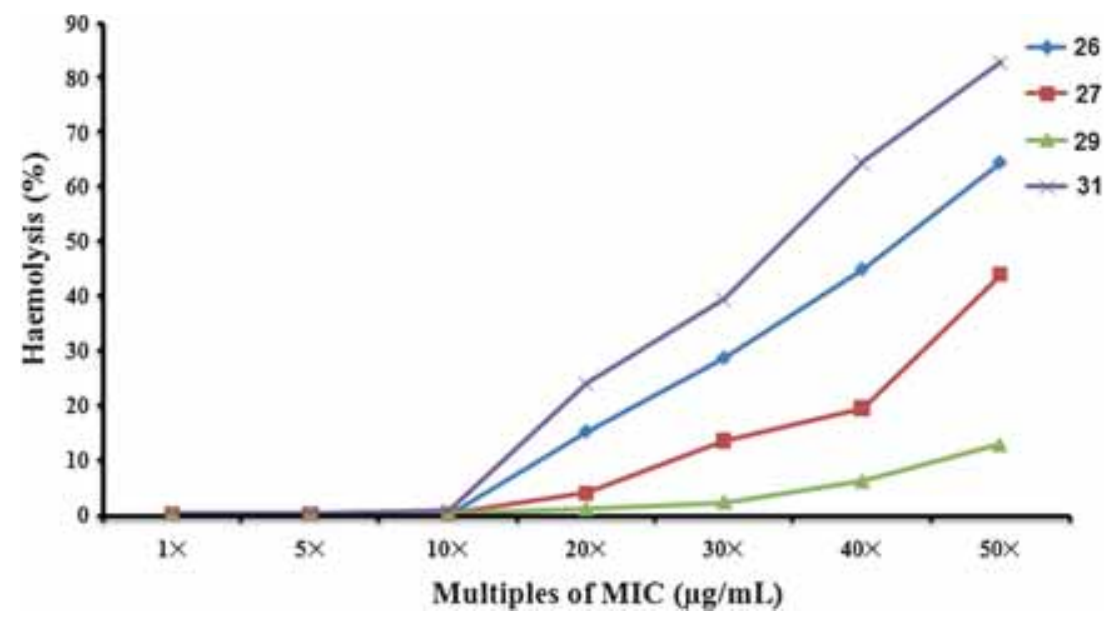

Figure 3. Cytotoxicity of active compounds against human erythrocytes by haemolytic assay. $0.1 \%$ Triton-X and PBS were used as a positive and negative control, respectively.

\section{Conclusions}

A series of novel quaternary ammonium derivatives of triazolyl pyranochromen-2-ones were synthesized and characterized from their physical and spectral data $\left({ }^{1} \mathrm{H}\right.$ NMR, ${ }^{13} \mathrm{C}$ NMR, ${ }^{2} \mathrm{D}$ NMR, UV, FT-IR and HRMS) analysis. To get insights of the antibacterial activity, the synthesized compounds and their bromoprecursors were screened against two gram-positive bacterial strains ( $S$. aureus and B. cereus) and two gramnegative bacterial strains ( $P$. aeruginosa and $E$. coli). The compounds having longer alkyl chain spacer $(\mathrm{n}=$ 10) were found to be more active as compared to the analogues having $\mathrm{n}=6$. By varying the substituents at the C-10 position of pyranochromen-2-ones with $\mathrm{H} / \mathrm{OH} / \mathrm{OMe}$, the antibacterial activity follows the order $\mathrm{H}>\mathrm{OCH}_{3}>\mathrm{OH}$. The compound 27 was found to be the most active with MIC values $8-12 \mu \mathrm{g} / \mathrm{mL}$ against the studied bacterial strains. The Cytotoxicity results revealed that these compounds are reasonably safe at their respective MIC values as it caused lysis maximum $24 \%$ at $20 \times$ MIC for B. cereus. Compound 27 exhibited the least toxicity (20\%) even up to concentration 40 times of its MIC value. This preliminary information can be used for the suitable modifications and for the further development of more promising antibacterial pharmacophores having a higher therapeutic index.

\section{Acknowledgements}

We gratefully acknowledge the financial assistance from the University of Delhi for the DU-DST PURSE Grant and Council of Scientific and Industrial Research (CSIR) task force project (BSC0302). The author PY is thankful to
Council of Scientific and Industrial Research (CSIR, New Delhi) for the award of Junior/Senior Research Fellowships.

\section{References}

1. McDonnell G and Russell A D 1999 Antiseptics and Disinfectants: Activity, Action, and Resistance Clin. Microbiol. Rev. 12147

2. Demberelnyamba D, Kim K, Choi S, Park S Y, Lee H, Kimb C J and Yoo I D 2004 Synthesis and antimicrobial properties of imidazolium and pyrrolidinonium salts Bioorg. Med. Chem. 12853

3. Kourai H, Yabuhara $T$, Shirai A, Maeda $T$ and Nagamune H 2006 Syntheses and antimicrobial activities of a series of new bis-quaternary ammonium compounds Eur. J. Med. Chem. 41437

4. Thorsteinsson $\mathrm{T}$, Masson $\mathrm{M}$, Kristinsson $\mathrm{K}$ G, Hjalmarsdottir M A, Hilmarsson $\mathrm{H}$ and Loftsson $\mathrm{T}$ 2003 Soft antimicrobial agents: Synthesis and activity of labile environmentally friendly long chain quaternary ammonium compounds J. Med. Chem. 464173

5. Gilbert P and Al-Taae A 1985 Antimicrobial activity of some alkyl-trimethyl ammonium bromides Lett. Appl. Microbiol. 1101

6. Bradbury B J and Pucci M J 2008 Recent advances in bacterial topoisomerase inhibitors Curr. Opin. Pharmacol. 8574

7. Patrick L, Ferroud D, Klich M, Dupuis-Hamelin C, Mauvais P, Lassaigne P, Bonnefoy A and Musicki B 1999 Synthesis and in vitro evaluation of novel highly potent coumarin inhibitors of gyrase B Bioorg. Med. Chem. Lett. 92079

8. Gupta S, Singh S, Kathuria A, Kumar M, Sharma S, Kumar R, Parmar V S, Singh B, Gupta A, Eycken E V D, Sharma G L and Sharma S K 2012 Ammonium derivatives of chromenones and quinolinones as lead antimicrobial agents J. Chem. Sci. 124437

9. Singh S, Gupta S, Singh B, Sharma S K, Gupta V K and Sharma G L 2012 Proteomic characterization of Aspergillus fumigatus treated with an antifungal 
coumarin for identification of novel target molecules of key pathways J. Proteome Res. 113259

10. Singh S, Dabur R, Gatne M M, Singh B, Gupta S, Pawar S, Sharma S K and Sharma G L 2014 In vivo efficacy of a synthetic coumarin derivative in a murine model of Aspergillosis PLoS One 9103039

11. Prasad S, Kumar S, Kumar B, Singh A K, Gautam H K and Sharma S K 2015 Quaternary ammonium and amido derivatives of pyranochromenones and chromenones: Synthesis and antimicrobial activity evaluation Med. Chem. Res. 242297

12. Damu G L V, Cui S F, Peng X M, Wen Q M, Cai G X and Zhou C H 2014 Synthesis and bioactive evaluation of a novel series of coumarinazoles Bioorg. Med. Chem. Lett. 243605

13. Shi Y and Zhou C H 2011 Synthesis and evaluation of a class of new coumarin triazole derivatives as potential antimicrobial agents Bioorg. Med. Chem. Lett. 21 956

14. Ronad P M, Noolvi M N, Sapkal S, Dharbhamulla S and Maddi V S 2010 Synthesis and antimicrobial activity of 7-(2-substituted phenylthiazolidinyl)-benzopyran-2-one derivatives Eur. J. Med. Chem. 4585

15. Raghu M, Nagaraj A and Reddy C S 2009 Synthesis and in vitro study of novel bis-[3-(2-arylmethylidenimino1,3-thiazol-4-yl)-4-hydroxy-2 $H$-chromen-2-one-6-yl] methane and bis-[3-(2-arylidenhydrazo-1,3-thiazol4-yl)-4-hydroxy-2H-chromen-2-one-6-yl]methane as potential antimicrobial agents J. Heterocycl. Chem. 46 261

16. Zhou C and Wang Y 2012 Recent researches in triazole compounds as medicinal drugs Curr. Med. Chem. 19239

17. Ahluwalia V K, Arora K K and Jolly R S 1982 Acid-catalysed condensation of isoprene with phenols.
Formation of 2,2-dimethylchromans J. Chem. Soc. Perkin Trans. 1335

18. Pechmann $\mathrm{H} \mathrm{V}$ and Duisberg C 1883 Uber die verbindungen der phenole mit acetessigather Chem. Ber. 162119

19. Waykole P and Usgaonkar R N 1982 Novel compounds from 4-formyl-6,7-dihydroxanthyletins: Synthesis of furobenzopyrandicarboxylic acids, 2- oxohexahydrofurofurobenzopyrans and 1-dihydroxanthyletinylmethyl-2-oxohexahydropyranobenzofuropyrrole Indian J. Chem. Sect B 8707

20. Pathak R, Kumar R and Gautam H K 2013 Cross-species induction and enhancement of antimicrobial properties in response to gamma irradiation in Exiguobacterium sp. HKG 126 Indian J. Microbiol. 53130

21. Yadav S, Mahato M, Pathak R, Jha D, Kumar B, Deka S R, Gautam H K and Sharma A K 2014 Multifunctional self-assembled cationic peptide nanostructures efficiently carry plasmid DNA in vitro and exhibit antimicrobial activity with minimal toxicity J. Mater. Chem. B 24848

22. Ciornei C D, Sigurdardottir T, Schmidtchen A and Bodelsson M 2005 Antimicrobial and chemoattractant activity, lipopolysaccharide neutralization, cytotoxicity and inhibition by serum of analogs of Human cathelicidin LL-37 Antimicrob. Agents Chemother. 492845

23. Dobrovolskaia M A, Clogston J D, Neun B W, Hall J B, Patri A K and McNeil S E 2008 Method for analysis of nanopaticle hemolytic properties in vitro Nano Lett. 8 2180

24. Himo F, Lovell $\mathrm{T}$, Hilgarf R, Rostovtsev V V, Noodleman L, Sharpless K B and Fokin V V 2005 Copper(I)-catalyzed synthesis of azoles. DFT study predicts unprecedented reactivity and intermediates J. Am. Chem. Soc. 127210 